\title{
Qualidade na Educação Básica: ações e estratégias dinamizadoras
}

\section{E्Eेuchão}

\begin{abstract}
Elton Luiz Nardi'
Marilda Pasqual Schneider'

Mônica Piccione Gomes Rios"

'Universidade do Oeste de Santa Catarina (UNOESC), Joaçaba/SC - Brasil "PontifíciaUniversidadeCatólicadeCampinas (PUC/Campinas), Campinas/SP-Brasil
\end{abstract}

RESUMO - Qualidade na Educação Básica: ações e estratégias dinamizadoras. O artigo tem por objetivo analisar ações e estratégias recorrentes, dinamizadas por escolas públicas de ensino fundamental com o propósito declarado de melhorar a qualidade da educação básica. Partindo dos resultados registrados por essas escolas em tradutores oficiais de qualidade, realça traços comuns entre medidas operadas a partir da publicação do Ideb de 2009, resultados escolares alcançados e variações nos índices e indicadores oficiais do período, sinalizando questões derivadas das tendências identificadas. Conclui demonstrando não haver correspondência uniforme entre ações dinamizadas e alcance de melhores índices oficiais, o que confirma a necessidade de um olhar atento ao que as escolas elegem como ações propulsoras de qualidade.

Palavras-chave: Qualidade da Educação Básica. Ações e Estratégias. Índices e Indicadores Oficiais.

ABSTRACT - Quality in Basic Education: motivating actions and strategies. The article aims to analyze recurrent actions and strategies, applied by public elementary schools with the stated purpose of improving the quality of basic education. Based on the results recorded by these schools in quality official translators, it highlights common traits between initiatives operated since the publication of the 2009 Ideb, results achieved and variations in official indexes and indicators of the period, signaling issues from the trends identified. It concludes showing no uniform correspondence between the actions taken and the achieving of better official rates, which confirms the need to look carefully at what the schools are electing as actions to drive quality.

Keywords: Quality of Basic Education. Actions and Strategies. Officials Indexes and Indicators.

Educação \& Realidade, Porto Alegre, v. 39, n. 2, p. 359-390, abr./jun. 2014. 


\section{Introdução}

Seguindo tendência internacional à intensificação de políticas de regulação da educação pela via de avaliações externas, o Brasil inaugurou, nas últimas décadas, diferentes indicadores de desempenho de estudantes, escolas e redes, na educação básica e superior, postulando o imperativo de assegurar um referencial de qualidade na educação. Alçada à condição de instrumento de gestão educacional, a avaliação assume, nesse contexto, posição de estratégia-chave (Sousa, 2003).

Na educação básica, desde 2007, o desenvolvimento educacional das escolas e redes públicas de ensino é aferido pelo Ideb (Índice de Desenvolvimento da Educação Básica). Dinamizados os mecanismos para sua composição, a expressividade desse índice ${ }^{1}$ nos âmbitos por ele focalizados tem sido associada ao seu potencial de traduzir, simbolicamente, o quanto as escolas e as redes avançam nas metas educacionais de qualidade. Razões como sua capacidade de detecção de escolas e redes nas quais seus estudantes apresentem baixa performance e de monitoramento da evolução temporal do desempenho dessas escolas ou redes justificariam, segundo seus idealizadores, a relevância da adoção desse índice oficial²

Postas em revista as recentes políticas que dão lugar destacado às avaliações em larga escala, ampliam-se e reforçam-se os debates acerca da qualidade na educação, tensionadas as abordagens que ancoram diferentes visões sobre o tema. É nesse contexto que reflexões sobre múltiplas determinações que afetam as condições de ensino e de aprendizagem nas escolas e que, portanto, realçam dimensões intra e extraescolares, ganham lugar no debate sobre a qualidade, nomeadamente desde uma perspectiva social (Dourado; Oliveira, 2009).

Conquanto o discurso oficial venha sinalizando permeabilidade à abordagem da qualidade social da educação e à observância de determinações que implicam o processo educativo escolar, as evidências dão conta que o referencial de qualidade de maior força no contexto das recentes políticas educacionais é o expresso pelo Ideb, que combina dois indicadores de natureza quantitativa (aprovação e desempenho) e ancora-se em um sistema de avaliação externo à escola.

Com a tendente consolidação desse referencial, redes de ensino e escolas são desafiadas ao uso das informações obtidas para a formulação de políticas e de planejamento educacional, sendo-lhes devido, por compromisso político-pedagógico, observar singularidades, necessidades e objetivos almejados pela comunidade escolar.

Tendo em vista esse cenário e os desafios que projeta sobre a escola e sua dinâmica, o presente trabalho tem por objetivo analisar ações e estratégias recorrentes, dinamizadas por um conjunto de escolas públicas de ensino fundamental, com o propósito declarado de melhorar a qualidade da educação. Partindo dos resultados registrados por essas escolas em tradutores oficiais de qualidade - Ideb e seus indicadores -, 
realça traços comuns entre medidas operadas a partir da publicação do Ideb de 2009, resultados escolares alcançados e variações nos índices e indicadores oficiais dos anos de 2009 e 2011.

Para tanto, toma por base resultados da primeira etapa de uma pesquisa vinculada ao Programa Observatório da Educação (Obeduc) ${ }^{3}$, cuja proposta consiste em avaliar a potencialidade e o alcance de estratégias e ações deflagradas por redes e escolas municipais de ensino fundamental da mesorregião oeste de Santa Catarina, visando à melhoria da qualidade na educação.

Atentos à realidade das escolas de ensino fundamental, a análise abrigada pelo objetivo traçado para o estudo tem em conta: os índices de desenvolvimento educacional por elas registrados no período de 2005 a 2011; os respectivos indicadores de desempenho e rendimento do mesmo período; as ações e estratégias sinalizadas pelos gestores dessas escolas a partir da publicação dos índices e indicadores, em 2010, bem como resultados alcançados com a implementação dessas ações e estratégias.

Em acordo a essa orientação, na parte inicial do trabalho trazemos reflexões atinentes ao tema da qualidade na educação, aos meios atribuídos pelas políticas educativas das últimas décadas para a construção da qualidade e ao uso dos dados oficiais, pelas escolas, como contribuição para um diagnóstico que oriente as ações no processo educativo.

Na sequência, apresentamos e analisamos os índices de desenvolvimento educacional e os indicadores que os compõem, relativamente ao conjunto de escolas públicas pesquisadas, de modo a destacar aspectos que informam recorrências e traços comuns nesse conjunto.

Por fim, exploramos as ações e estratégias deflagradas pelas escolas com o propósito da melhoria da qualidade da educação, cotejando-as com resultados que gestores declaram terem alcançado e com variações nos índices e indicadores oficiais ocorridos nos anos de 2009 e 2011.

\section{Indicadores de Qualidade da Educação: um debate em aberto}

Embora o tema da qualidade na educação não seja novo, como evidencia a produção de textos publicados nas últimas décadas, seu significado segue marcado pela polissemia, por uma imprecisão conceitual e, não raro, pela ambiguidade. Consoante comentam Oliveira e Araújo (2005, p. 5), até mesmo entre especialistas “[...] é difícil chegar-se a uma noção do que seja qualidade de ensino”, dado se tratar de um produto histórico, construído socialmente, que reflete posicionamentos políticos e ideológicos orientados por diferentes setores e com perspectivas diversas.

Apesar das imprecisões que cercam o tema, estudos desenvolvidos por Dourado, Oliveira e Santos (2007), Dourado e Oliveira (2009)

Educação \& Realidade, Porto Alegre, v. 39, n. 2, p. 359-390, abr./jun. 2014.

Disponível em: <http://www.ufrgs.br/edu_realidade> 
Qualidade na Educação Básica

entre outros, evidenciam que as políticas educacionais encampadas no país, neste início de século XXI, têm sido permeáveis ao conceito de qualidade social, especialmente na educação básica.

É certo que pensar a qualidade implica considerar o uso de medidas comparativas que permitam distinguir entre o que seria uma boa ou uma má qualidade, posto que ela é mais facilmente percebida pela falta de, ou seja, pelos atributos ${ }^{4}$ que não atendem aos padrões considerados adequados, do que pela presença deles. Vistas por esse ângulo, quantidade e qualidade constituem elementos inseparáveis, embora esses não possam e não devam ser confundidos (Azevedo, 2011).

No âmbito das recentes políticas educacionais brasileiras, temos evidenciado a tendência ao desenvolvimento de ações e programas que reforçam a tradução da qualidade por meio de atributos passíveis de serem medidos. Essa tendência parece negligenciar, na maioria das vezes, a tensão do binômio quantidade-qualidade e suas implicações na escola.

No entanto, não é apenas nas últimas duas ou três décadas que a ideia da qualidade parece alinhar-se mais com indicadores que permitam apreender seu conteúdo por atributos predominantemente quantitativos. Consoante destacam Oliveira e Araújo (2005, p. 8), o problema da qualidade tornou-se "[...] central no debate educacional a partir da década de 1940, quando teve início, inclusive no Brasil, um processo significativo de expansão das oportunidades de escolarização". Talvez, por isso, naquele contexto histórico, a noção de qualidade na política erigida tenha sido vinculada às condições de ampliação das oportunidades de escolarização e de expansão da rede de escolas.

Como se sabe, as políticas encampadas a partir dessa interpretação desaguaram no problema de fluxo escolar. A expansão desordenada de escolas públicas, predominante nas décadas de 1940 a 1960, foi acompanhada de taxas mais elevadas de repetência e evasão escolar, especialmente nos anos iniciais do ensino fundamental.

Na tentativa de orientar a educação brasileira por outra perspectiva, na década de 1980 o indicador de qualidade passou a não mais tomar como referência o acesso, mas, sim, a permanência dos alunos no sistema educacional. Erigiu-se, então, um novo atributo para aferir a qualidade "[...] definido como número de alunos que progridem dentre de determinado sistema de ensino" (Oliveira; Araújo, 2005, p. 10). A opção abraçada impulsionou a produção de políticas e programas brasileiros de aprovação automática e de aceleração da aprendizagem.

Não obstante, na década de 1980, a aferição da qualidade da educação básica brasileira continuou uma questão não resolvida. Se as possibilidades de ingresso na escola tornaram-se mais acessíveis a partir das políticas da segunda metade do século passado, o mesmo não ocorreu com as condições de permanência e avanço nas diferentes séries escolares. Conquanto houvesse esforços para aumentar as taxas de aprovação, as de reprovação e abandono continuaram preocupantes 
nas décadas seguintes, especialmente no ensino médio, conforme se verifica no Gráfico 1.

Gráfico 1 - Evolução das Taxas de Reprovação e Abandono no Ensino Fundamental e Médio - Brasil - 1997 a 2011

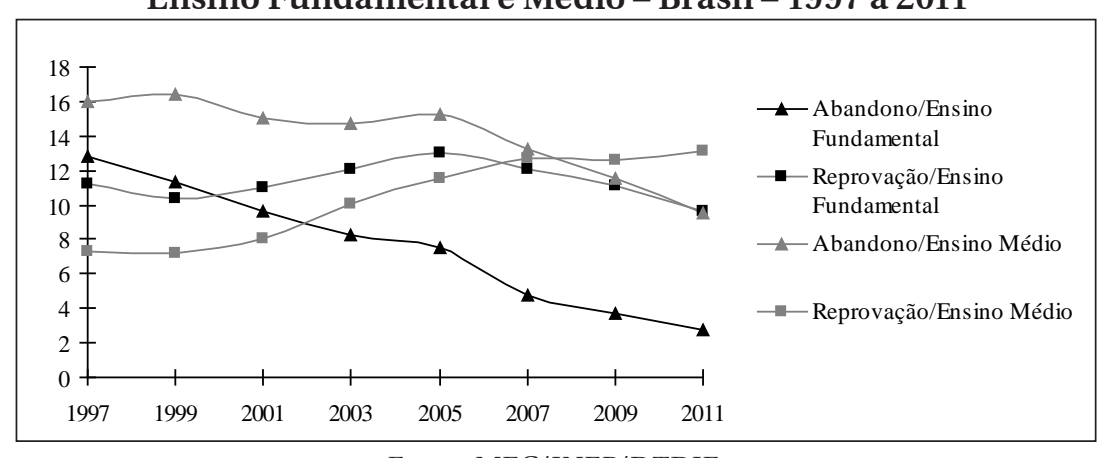

Fonte: MEC/INEP/DTDIE.

Em suma, se a partir das políticas empreendidas na segunda metade do século passado a escola tornou-se mais acessível aos menos favorecidos economicamente, a melhoria das condições de permanência e avanço nas diferentes séries escolares ocorreu em proporção diferente. Daí que, na década de 1990, sob o argumento da difícil tarefa de aferir a qualidade pelos indicadores de fluxo, um novo indicador passou a ganhar centralidade, definido a partir de avaliações externas à escola. A partir de então, a aferição da qualidade da educação básica passou a relacionar-se aos resultados logrados pelos estudantes em testes nacionais.

Do ponto de vista das políticas educacionais empreendidas a partir da primeira década deste século, a qualidade continua a ser traduzida por indicadores pautados por critérios predominantemente quantitativos. Ainda que se advogue em favor de uma qualidade social na educação, conforme aludem, por exemplo, as Diretrizes Curriculares Gerais para a Educação Básica (Brasil, 2010c) e defendem estudiosos do tema, o conceito de qualidade em curso vem fundado em indicadores específicos, medidos objetivamente e por agentes externos à escola, a despeito do contributo de outros indicadores que tenham em conta o contexto e as peculiaridades das escolas.

Consoante o curso das políticas aqui referidas, em 2007, por meio do Decreto n. 6.094, que dispõe sobre a implementação do Plano de Metas Compromisso Todos pela Educação, foi criado o Ideb. De acordo com o Decreto, a qualidade da educação básica será aferida, objetivamente, com base nesse índice.

No caso dos municípios e das escolas públicas de ensino fundamental, sua composição resulta do produto de dois indicadores - o desempenho dos alunos na Prova Brasil (N) e o rendimento escolar (P). O primeiro compreende a média da proficiência em Língua Portuguesa e 
Matemática, expressa em uma escala de 0 e 10 . O segundo toma a taxa de aprovação dos alunos na etapa de ensino, aferida por meio do Censo Escolar, e é expressa por valores entre 0 e 1.

A despeito dos diferentes posicionamentos de estudiosos da área sobre a potencialidade do indicador para os propósitos de qualidade almejados (Saviani, 2007; Portela, 2008; Sousa, 2008), parece haver razoável consenso de que a criação de um instrumento de aferição do desenvolvimento da educação básica representa avanço significativo nas condições de acompanhamento e monitoramento da situação educacional brasileira. Ainda assim, recaem reservas candentes sobre o papel exercido pelas avaliações externas no âmbito escolar, ou seja, na interface com escolas e professores (Freitas et al., 2011).

De todo modo, em vista da condição do Ideb de tradutor oficial da qualidade da educação básica, tem sido a partir desse índice que as escolas vêm sendo chamadas a propor medidas visando ao alcance de melhores resultados educacionais. Esses resultados, por sua vez, encontram-se perspectivados em metas traçadas pelo Estado brasileiro e pactuadas entre o MEC e as unidades subnacionais.

Sob o ângulo da função creditada ao Ideb e a seu papel nos contextos locais, diremos que ações e estratégias de iniciativa das escolas e redes públicas de educação básica não só são esperadas como devem focalizar condições potencialmente conducentes à melhoria dos indicadores submetidos à aferição.

Ao tempo em que se pode indagar acerca do projeto de qualidade em favor do qual operam essas ações e estratégias, somos levados a problematizar tanto as circunstâncias que concorrem para a determinação do prioritário para a escola como a apropriação, pelos sujeitos escolares, dos resultados oficiais que informam a qualidade da educação.

\section{Índices e Indicadores Oficiais das Escolas Pesquisadas}

No ano de 2009 ocorreu a terceira aferição do Ideb. No entanto, sua divulgação à nação brasileira ocorreu em 2010. Embora a existência do índice já estivesse suficientemente disseminada, dado seu caráter inovador apontado por Fernandes e Gremaud (2009) e a ênfase à aferição da qualidade da educação básica por meio de avaliações estandardizadas, a engenharia de constituição do índice ainda não era (e talvez ainda não seja) completamente compreendida pelas escolas em geral.

A despeito disso, os números alcançados pela maioria dos estados brasileiros no Ideb de 2009, quando comparados aos dos biênios anteriores de sua aferição, indicavam avanços importantes em todas as etapas da educação básica avaliadas. De acordo com Inep, esses avanços se deviam, em boa medida, ao aumento das notas na Prova Brasil, que foi de $71,1 \%$ nos anos iniciais, $64 \%$ nos anos finais e $57,9 \%$ no ensino médio (Brasil, 2010b). 
Na esteira dos avanços logrados em 2009, os números do Ideb de 2011 indicaram que as metas nacionais foram atingidas. Nos anos iniciais, o Ideb atingiu nota 5,0, portanto superior à meta de 4,6 e também à de 2013, fixada em 4,9 pontos. Nos anos finais, o índice nacional alcançou 4,1 pontos, um pouco superior à meta estabelecida, de 3,9 (Brasil, 2012).

Embora os resultados possam ser comemorados em seu conjunto, é imprescindível submetê-los a uma análise detalhada e criteriosa quando tomados contextos específicos. Isso porque, ainda que apontem avanços nos índices educacionais, os resultados são menos expressivos nos anos finais e no ensino médio do que nos anos iniciais. Esse é justamente o caso do conjunto de escolas de ensino fundamental, representante de 18 municípios da mesorregião oeste catarinense.

Além disso, chama atenção o quadro díspar, conforme indicam os dados do Gráfico 2, relativos aos anos iniciais, visto que as escolas amostradas e seus municípios, em geral, guardam características socioeconômicas e culturais muito próximas.

Gráfico 2 - Ideb dos Anos Iniciais do Ensino Fundamental - 2005, 2007, 2009 e 2011

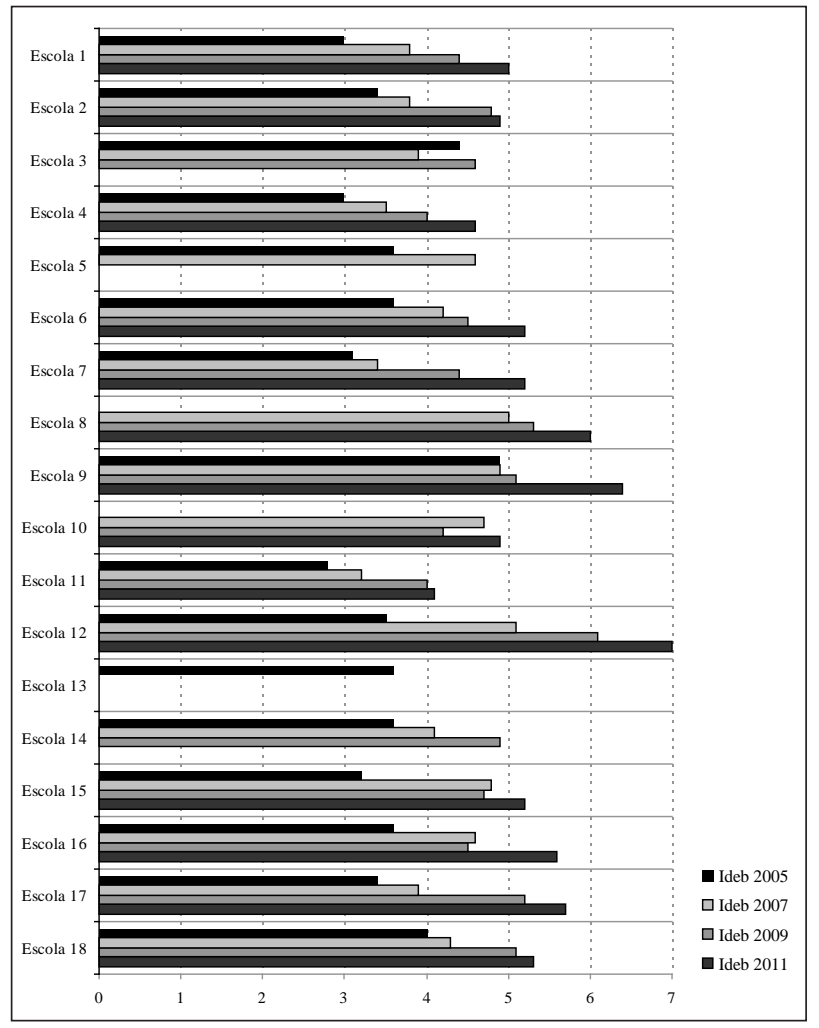

Fonte: MEC/Inep.

Educação \& Realidade, Porto Alegre, v. 39, n. 2, p. 359-390, abr./jun. 2014.

Disponível em: <http://www.ufrgs.br/edu_realidade> 
Afora o quadro díspar que caracteriza o conjunto, nos anos iniciais, as escolas amostradas vêm demonstrando crescimento significativo do seu Ideb. A grande maioria se destaca no crescimento alcançado ao longo dos quatro biênios de aferição. Há que se registrar que, em 2011, a proporção de 0,93 do conjunto de escolas ultrapassou a meta projetada para 2013. Essa mesma proporção atingiu a meta nacional para os anos iniciais e, a proporção de 0,71, a média alcançada em nível nacional para essa etapa do ensino fundamental.

Já em relação aos resultados alcançados pelas escolas nos anos finais do ensino fundamental, os dados são menos expressivos, preservado o referido quadro díspar. Entre as escolas que oferecem os anos finais, somente a proporção de 0,67 do conjunto melhorou o índice dessa etapa escolar, conforme ilustra o Gráfico 3.

Gráfico 3 - Ideb dos Anos Finais do Ensino Fundamental - 2005, 2007, 2009 e 2011

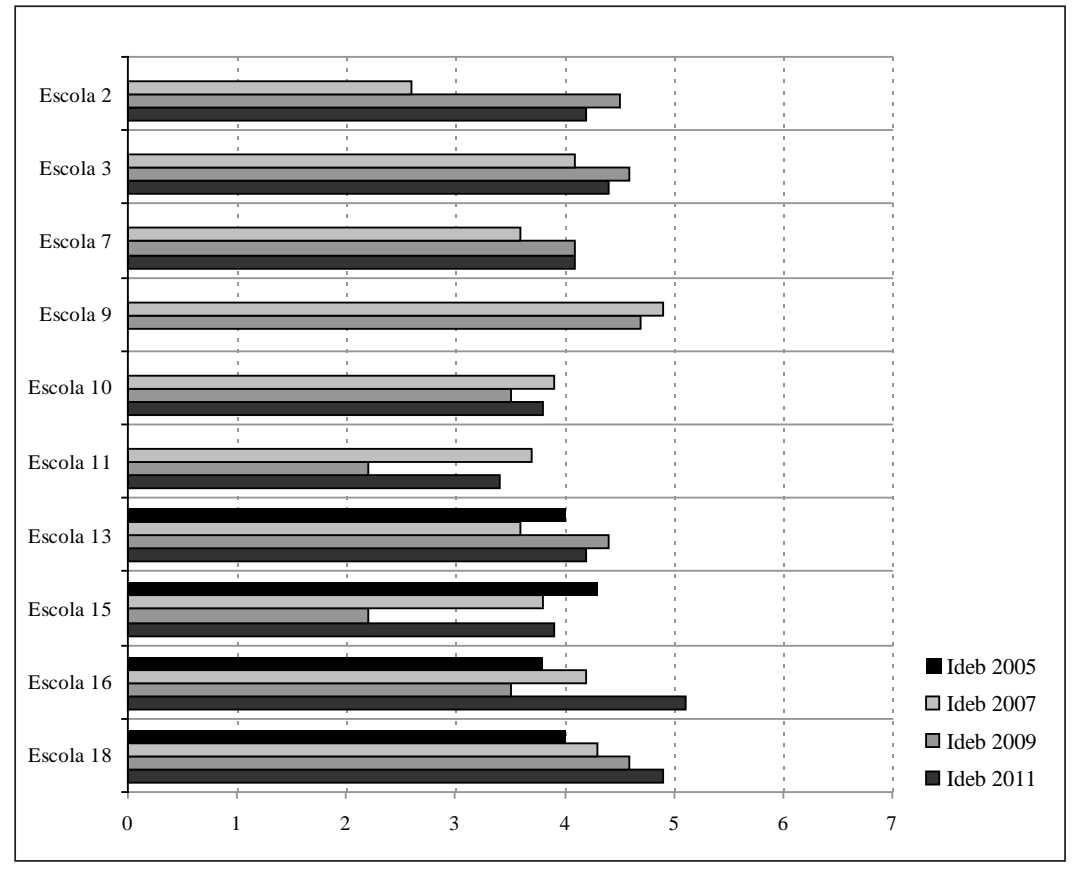

Fonte: MEC/Inep.

Esses são dados que, quando comparados aos dos anos iniciais, revelam um quadro bastante distinto, especialmente se tomarmos os resultados obtidos em 2009 e 2011. Das escolas que também apresentaram Ideb nos anos finais em 2011, cerca de 0,5 desse conjunto ficou abaixo da meta projetada para o mesmo ano, ainda que a proporção de 0,56 tenha registrado um crescimento entre 6,5 e 54,5\% no índice. Pelos resultados apresentados, presume-se que elas enfrentam dificuldades 
para assegurar e ou obter desempenho satisfatório nos exames dos anos finais. A persistir o quadro anunciado, várias dessas escolas possivelmente não alcançarão a meta nacional para 2021, o que significa dizer que, em vista da crescente tendência à tradução da qualidade por meio de atributos quantitativos, sobre elas persiste um quadro que é, no mínimo, desafiador.

Atentos ao fato de que a pontuação no Ideb depende da composição articulada entre desempenho e rendimento e que, nesse sentido, o esforço esperado da escola é para que consiga equilíbrio entre ambos, já que o índice é “[...] explícito em relação à 'taxa de troca' entre probabilidade de aprovação e proficiência dos estudantes” (Fernandes, 2007, p. 8), importa revistarmos os dados desses indicadores relativos às escolas pesquisadas.

Ao recorrermos à pontuação média obtida pelos estudantes na Prova Brasil (indicador de desempenho), a complexidade informada pelo conjunto também esclarece em boa medida a composição do quadro díspar que caracteriza, sob o ângulo da política de avaliação da qualidade instaurada com o Ideb, o desenvolvimento educacional das escolas. A baixa pontuação na proficiência em Matemática e Língua Portuguesa, ainda que em ascensão em alguns casos, é inequivocamente o eixo da questão.

Relativamente aos anos iniciais, somente duas de 14 escolas que participaram da Prova Brasil em 2011 diminuíram a pontuação na proficiência em Língua Portuguesa, comparativamente à edição da prova de 2009, embora tenham ampliado o Ideb em 0,1 ponto em vista de aumento nas taxas de aprovação. Nas demais escolas, o crescimento na pontuação variou entre 1,98 e 27,91 pontos, resultando no aumento do Ideb em todas elas (entre 0,2 e 1,3 ponto), mesmo naquelas em que as taxas de aprovação diminuíram ou não foram alteradas no período. No quadro geral, conforme ilustra o Gráfico 4, somente a proporção de 0,28 do conjunto das escolas participantes da Prova Brasil 2011 alcançou pontuação superior a 200 pontos, faixa considerada desejável ${ }^{5}$, o que representa posicionamento majoritário no nível 4 da escala de proficiência, demarcada em 9 níveis. 
Gráfico 4 - Pontuação Obtida pelos Estudantes de $4^{\mathrm{a}}$ série/5º ano do Ensino Fundamental na Proficiência em Língua Portuguesa Prova Brasil de 2005 a 2011

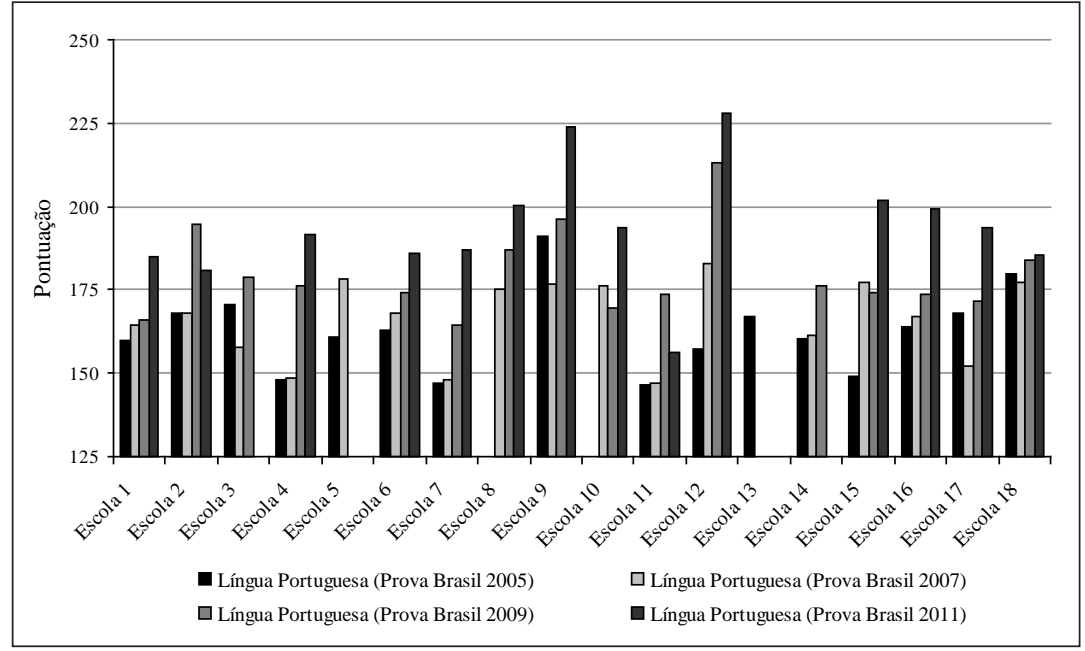

Fonte: MEC/Inep.

Nos anos iniciais, a disparidade entre índices e indicadores de desenvolvimento educacional, além de encontrar base nas acentuadas variações da pontuação média obtida pelos estudantes entre as escolas investigadas, caracteriza-se pela preponderância de baixos níveis de proficiência em Língua Portuguesa em todos os biênios de aferição do Ideb.

No que concerne aos níveis de proficiência em Matemática, a pontuação obtida pelos estudantes de $4^{\mathrm{a}}$ série $/ 5^{\mathrm{o}}$ ano do ensino fundamental, na Prova Brasil de 2011, revela um quadro um pouco mais auspicioso quando comparado à desenvoltura desses mesmos estudantes na proficiência em Língua Portuguesa.

De acordo com os dados do Gráfico 5, em todas as escolas que registraram Ideb em 2011 houve aumento da pontuação obtida pelos estudantes dos anos iniciais na disciplina de Matemática. $\mathrm{O}$ aumento obtido, em relação a 2009, esteve compreendido entre 2,93 e 46,62 pontos, uma faixa mais alargada à que compreendeu o aumento em Língua Portuguesa. 
Gráfico 5 - Pontuação Obtida pelos Estudantes de $4^{\mathrm{a}}$ série $/ 5^{\circ}$ ano do Ensino Fundamental na Proficiência em Matemática - Prova Brasil de 2005 a 2011

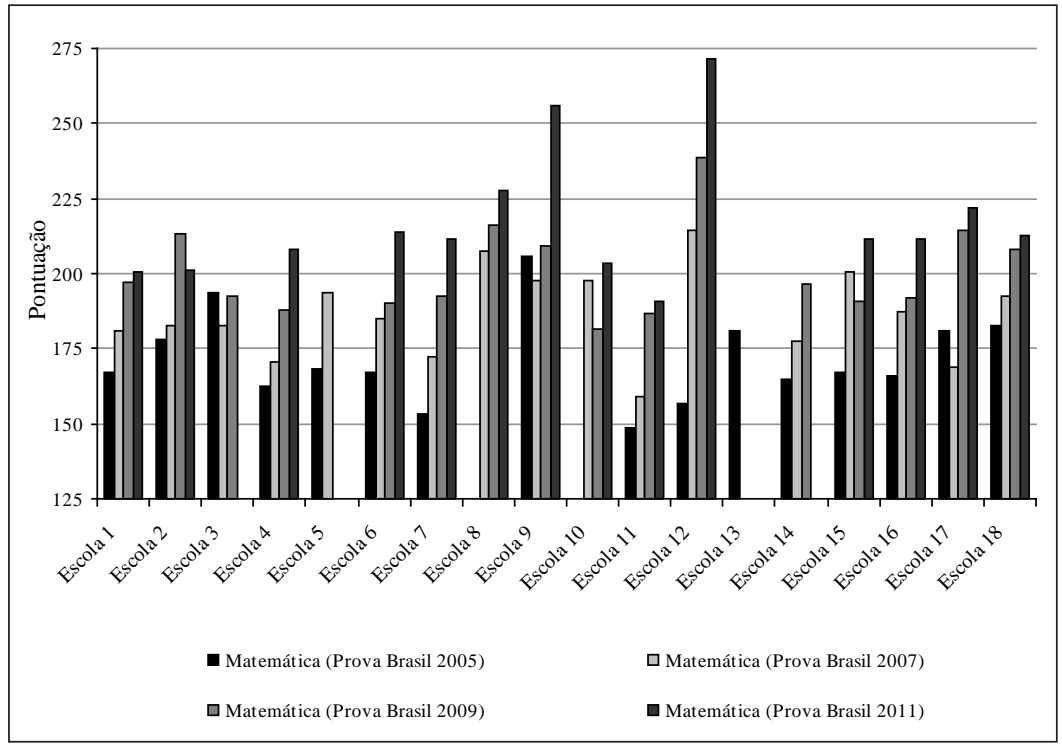

Fonte: MEC/Inep.

Não obstante o aumento verificado, somente a proporção de 0,21 das escolas com Ideb em 2011 alcançou pontuação superior a 225 pontos, faixa considerada desejável para a disciplina de Matemática. Considerando a lógica que orienta o Ideb, o posicionamento de 0,79 do universo de escolas no nível 4 da escala de proficiência (entre 200 e 225 pontos) sinaliza um cenário ainda preocupante em termos de domínio dos conhecimentos da área demonstrado pelos estudantes dos anos iniciais.

Na esteira do que expressam os números do Ideb, em relação aos anos finais as notas padronizadas da Prova Brasil tenderam a ficar abaixo dos referenciais sinalizados como pontuação desejável, tanto em Língua Portuguesa quanto em Matemática.

No Gráfico 6 visualizamos os dados relativos à pontuação nessa etapa do ensino fundamental, na proficiência em Língua Portuguesa. Somente 10 escolas do conjunto de 18 mantiveram atendimento nos anos finais em 2011 e somente nove delas registraram pontuação na Prova Brasil. 
Gráfico 6 - Pontuação Obtida pelos Estudantes de $8^{\mathrm{a}}$ série/9o ano do Ensino Fundamental na Proficiência em Língua Portuguesa Prova Brasil de 2005 a 2011

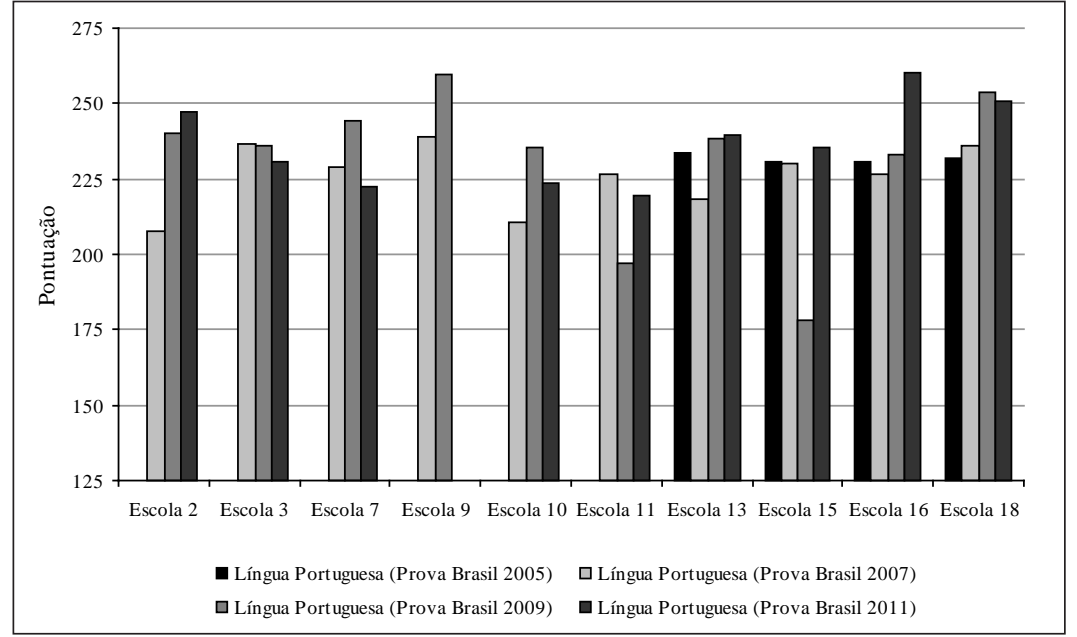

Fonte: MEC/Inep.

Comparativamente ao ano de 2009, os números de 2011 expressam uma maior aproximação entre as escolas pesquisadas e um pequeno avanço em termos de pontuação, na medida em que, em 2009, a proficiência em Língua Portuguesa foi informada por uma pontuação que ficou entre 178,14 e 259,92 pontos.

Por outro lado, a exemplo dos biênios anteriores, pesam desfavoravelmente as baixas pontuações registradas. Estas, em 2011, estiveram compreendidas entre 219,7 e 260,39 , majoritariamente entre os níveis 4 e 5 da escala de proficiência. O que está indicado como desejável para essa área do conhecimento e etapa do ensino fundamental é uma pontuação igual ou superior a 275 pontos. Assim, ainda que se observe um aumento na pontuação de Língua Portuguesa a cada biênio, essa pontuação alcança apenas níveis mínimos de proficiência em leitura.

O quadro dos indicadores de desempenho em Língua Portuguesa não dista do informado em Matemática, conforme se verifica nos dados do Gráfico 7. 


\section{Gráfico 7 - Pontuação Obtida pelos Estudantes de 8ª́rie/9o Ano do Ensino Fundamental na Proficiência em Matemática - Prova Brasil de 2005 a 2011}

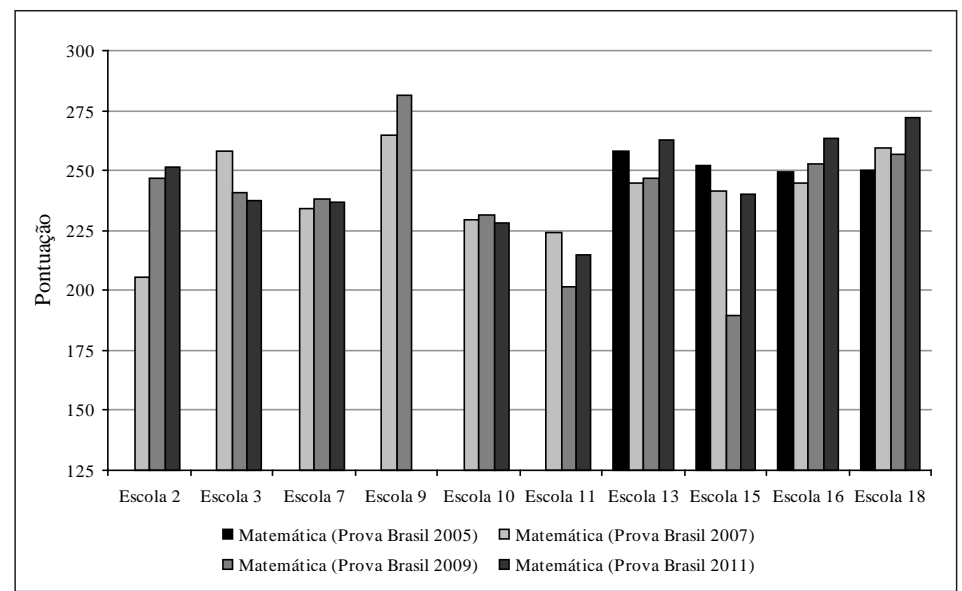

Fonte: MEC/Inep.

Os números que formalmente traduzem o desempenho dos estudantes no campo da Matemática sinalizam, inclusive, um quadro ainda mais preocupante. Nesse caso, a variação entre a menor e a maior pontuação obtida na última Prova Brasil foi de 48,53 pontos, aproximadamente $20 \%$ maior que a diferença registrada na disciplina de Língua Portuguesa.

No que concerne aos indicadores de rendimento, os dados indicam que as escolas têm ampliado consideravelmente a taxa de aprovação nos biênios de 2005 a 2011, assim como promovido maior aproximação entre indicadores, em termos de valores, conforme podemos visualizar no Gráfico 8.

Gráfico 8 - Menores e Maiores Indicadores de Rendimento dos Anos Iniciais e dos Anos Finais do Ensino Fundamental Registrados no Conjunto de Escolas Pesquisadas - 2005 a 2011

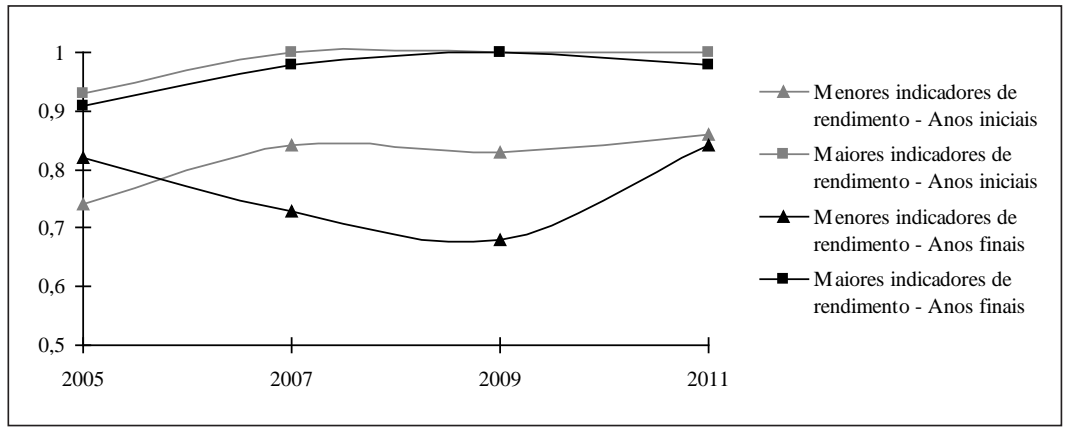

Fonte: MEC/Inep. 
Em síntese, pelos dados até aqui apresentados, nas escolas pesquisadas os índices e indicadores relativos à etapa dos anos iniciais têm sido melhores que os registrados na dos anos finais. É também aquela etapa que registra maiores taxas de aprovação, conforme ilustra o Gráfico 8, e a que mantém mais estável, ao longo dos biênios, a distância entre o menor e o maior indicador de rendimento registrado a cada edição do Ideb.

De todo modo, ainda que os dados do Ideb das escolas pesquisadas apresentem um quadro evolutivo em relação às metas traçadas, especialmente quanto à etapa dos anos iniciais, na maioria delas persiste o desafio de melhoria nos níveis de apropriação da capacidade de leitura e resolução de problemas, representados pelo desempenho dos estudantes na Prova Brasil. A disparidade entre os índices e indicadores das escolas, em contextos socioeconômicos e culturais muito próximos é, sem dúvida, outro aspecto preocupante e merecedor de estudos mais apurados.

Esse é um aspecto que, visto do ângulo do monitoramento da situação educacional brasileira, possível de ser desempenhado por um recurso de aferição do desenvolvimento da educação básica (Freitas et al., 2011), não deve ser desconsiderado. Afinal, nesse sentido, o recurso sinaliza para a interface entre comunidade escolar e políticas educacionais na definição de indicadores que figurem como referenciais para a construção da qualidade social (pretensamente almejada), o que contrasta com o direcionamento que as políticas educacionais recentes tendem a conferir ao recurso, segundo o qual as provas estandardizadas constituem peça primeira de aferição da qualidade, requerida adequação das escolas a padrões de qualidade traçados externamente a ela.

É com o quadro e as tensões aqui referidos que gestores e professores da educação básica tem sido chamados, com tom de responsabilização, a implementar ações e estratégias que possibilitem o alcance de melhores resultados educacionais, assim como convocados a agir em atenção ao projeto político-pedagógico construído pela comunidade escolar para orientar o processo educativo.

Que ações e estratégias essas escolas têm buscado implementar, orientadas pelo propósito de melhoria da qualidade da educação? Que recorrências e que traços comuns podem ser identificados entre elas, em termos de ações e estratégias eleitas e de resultados alcançados? Essas são algumas questões de fundo que buscamos discutir a partir de agora, atentos a possíveis relações entre estímulos da política educacional, por força da produção e disseminação dos índices e indicadores oficiais, e respostas oferecidas pelo conjunto de escolas, por meio de ações e estratégias delineadas em seus contextos. 


\section{Ações e Estratégias Propostas pelas Escolas}

As ações e estratégias eleitas pelas escolas a partir dos resultados do Ideb de 2009 foram informadas por seus gestores, nos meses finais de 2011 e iniciais de 2012, por meio de questionários eletrônicos ${ }^{6}$.

Com vistas a identificar especificidades dessas ações e estratégias, os gestores escolares foram chamados a apontá-las em 11 eixos abarcados pelas seguintes dimensões: (I) infraestrutura escolar (condições físicas e recursos didático-pedagógicos); (II) gestão escolar (planejamento, recursos humanos, recursos financeiros e parcerias); (III) formação dos profissionais do magistério da educação básica (formação inicial e formação continuada); e (IV) práticas pedagógicas (organização escolar, organização didático-pedagógica e avaliação da aprendizagem). Para cada eixo, foi facultado aos gestores o registro de até três ações julgadas prioritárias, o que significa dizer que o sistema de recolha foi organizado para comportar a recepção de até 594 ações e estratégias.

Ao todo, os gestores registram 357 ações e estratégias, o que corresponde a $60,1 \%$ da capacidade preparada de recolha. Outros 201 campos de registro (33,8\%) foram dispensados pelos respondentes, em vista da opção pelo não preenchimento em um ou mais eixos ou mesmo da apresentação de apenas uma ou duas ações e estratégias em determinados eixos. Por fim, outras 36 possibilidades de registro $(6,1 \%)$ foram automaticamente eliminadas, considerando que, por 12 vezes, em um determinado eixo, não foram previstas ações e estratégias a partir da divulgação do Ideb, em 2010. Metade desses casos concentrou-se na dimensão III (formação dos profissionais do magistério da educação básica), e nesta, especialmente no eixo formação inicial. Sobre essa especificidade, a massiva maioria das justificativas ancora-se no fato de as escolas já possuírem corpo docente habilitado.

Das 357 ações e estratégias declaradas pelos gestores no formulário, os dados dão conta de que 34,2\% de ações já vinham, em parte, sendo implementadas antes dessa divulgação do Ideb e outras 17,9\% já haviam sido realizadas por completo antes de 2010. Do total de ações e estratégias informadas, $14,3 \%$ foram traçadas a partir da divulgação o Ideb, em 2010, e outras 33,6\% não foram devidamente identificadas em relação a esse aspecto.

Segundo os gestores, os problemas mais frequentes a que a escola se propôs a enfrentar visando à melhoria da qualidade da educação, e a partir dos quais teriam decorrido as ações e estratégias informadas, relacionam-se especialmente aos seguintes eixos, por ordem de recorrência: (1) recursos pedagógicos; (2) condições físicas; (3) planejamento; e (4) organização didático-pedagógica.

Após esse inventário, as ações e estratégias foram relacionadas por dimensão e eixo, de modo a buscar, sem prejuízo ao foco, certa padronização descritiva do conjunto. Nesse mesmo processo foram identificadas ações e estratégias sobrepostas ou mesmo repetidas para uma

Educação \& Realidade, Porto Alegre, v. 39, n. 2, p. 359-390, abr./jun. 2014. 373

Disponível em: <http://www.ufrgs.br/edu_realidade> 
mesma escola, assim como casos de registro em outros eixos e dimensões que não os correspondentes. No primeiro caso, foram eliminadas as repetições ou efetuados ajustes no registro. No segundo, as ações ou estratégias foram deslocadas para os eixos e dimensões apropriados, o que significa dizer que em alguns eixos, onde inicialmente não constavam registros, passou-se a considerar a presença de iniciativas por parte da respectiva escola.

Também nos casos de ações e estratégias cujos conteúdos evidenciavam presença de duas ou mais medidas, optamos por desmembrá-las de modo a conferir especificidade a cada uma. Isso ocorreu 21 vezes, sendo $62 \%$ dos casos concentrados na dimensão I (infraestrutura escolar). De outro modo, foram descartadas 31 ações ou estratégias descritas de forma vaga, ambígua ou imprecisa.

Assim, o processo de sistematização efetuado levou-nos à identificação de um conjunto de 130 tipos de ações e estratégias eleitos pelas escolas com o propósito de melhorar a qualidade da educação, sobre os quais resultaram 274 menções pelo grupo de gestores. O Gráfico 9 ilustra a distribuição dessas diferentes ações nas respectivas dimensões pesquisadas.

\section{Gráfico 9 - Percentual de Tipos de Ações Eleitas pelas Escolas, por} Dimensão

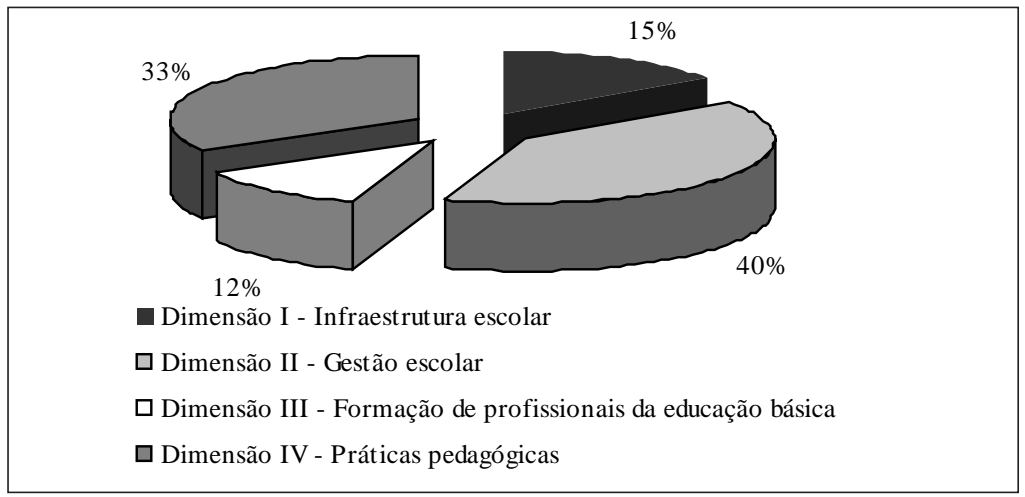

Fonte: organizado pelos pesquisadores com base nos questionários.

Como se pode observar, a Dimensão II (gestão escolar) é a que abarca a maior diversidade de ações ou estratégias apontadas pelo conjunto de gestores. Ademais, conforme se verifica no Gráfico 10, é nessa dimensão que se encontra registrado o maior número de ações indicadas pelos gestores (36,1\% do total). Por outro lado, se considerarmos o número de eixos em cada dimensão, a maior média de ações ou estratégias concentra-se na Dimensão I (infraestrutura escolar), com 45 ações por eixo. A menor média é a da Dimensão III (formação de profissionais da educação básica), com 11,5 ações por eixo, e o eixo com o menor número de ações é o da formação inicial, da mesma dimensão. A quantidade de ações indicadas neste eixo corresponde a menos de $1 \%$ do total. 


\section{Gráfico 10 - Número de Ações Eleitas pelas Escolas por Campo e Dimensão}

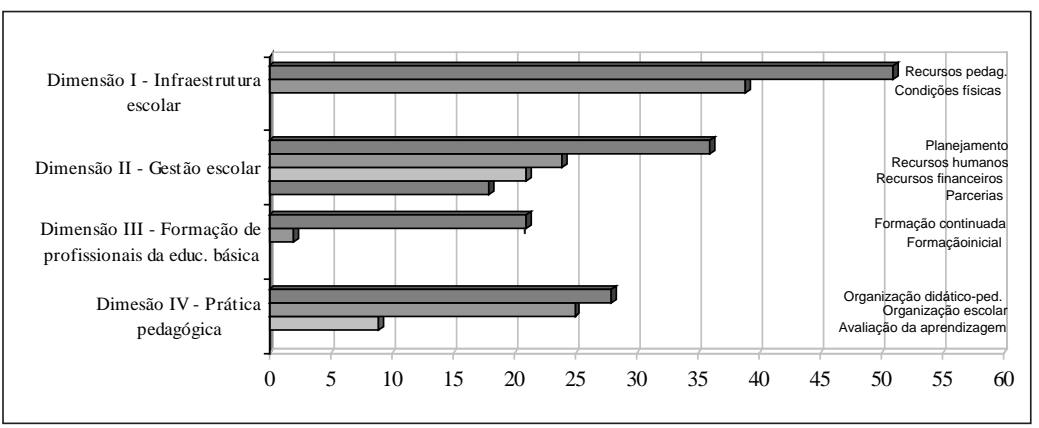

Fonte: organizado pelos pesquisadores com base nos questionários.

Das 274 ações ou estratégias mapeadas, 78 delas $(28,5 \%)$ foram citadas apenas uma vez, 16 tipos foram citados duas vezes (11,7\%) e outros 12 tipos foram mencionados três vezes pelos gestores $(13,1 \%)$. As demais foram referidas com frequência superior a $20 \%$, conforme indicam os Gráficos 11, 12, 13 e 14, que ilustram a distribuição dessas ações e estratégias segundo a dimensão a que pertencem. Consoante o objetivo desse estudo, os dados constituem o corpus das iniciativas operadas pelas escolas, a partir de 2010, com o propósito declarado de melhorar a qualidade da educação, e sobre as quais nossa análise incide daqui para frente.

\section{Gráfico 11 - Ações Relacionadas à Infraestrutura Escolar - mencionadas por mais de $20 \%$ dos gestores das escolas pesquisadas}

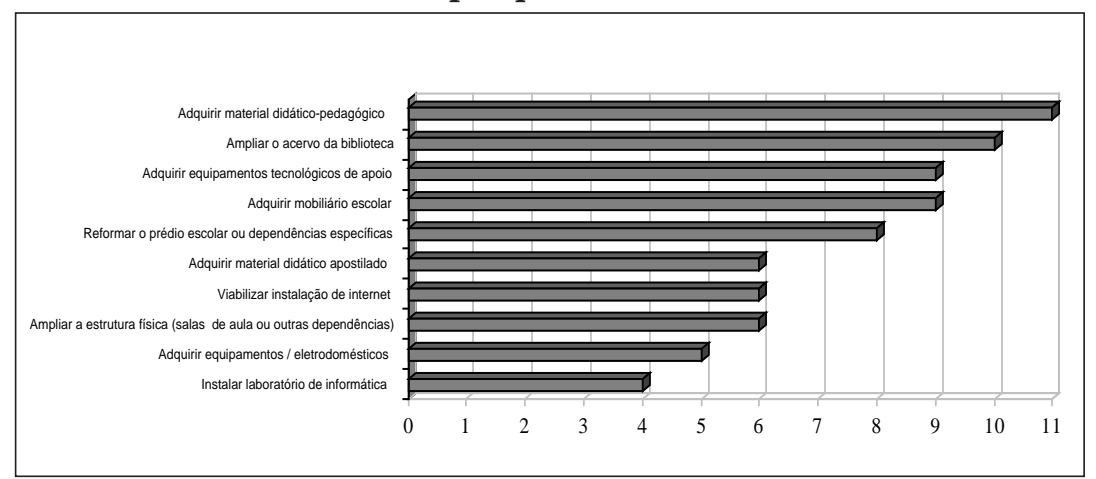

Fonte: organizado pelos pesquisadores com base nos questionários. 
Gráfico 12 - Ações Relacionadas à Gestão Escolar - mencionadas por mais de $20 \%$ dos gestores das escolas pesquisadas

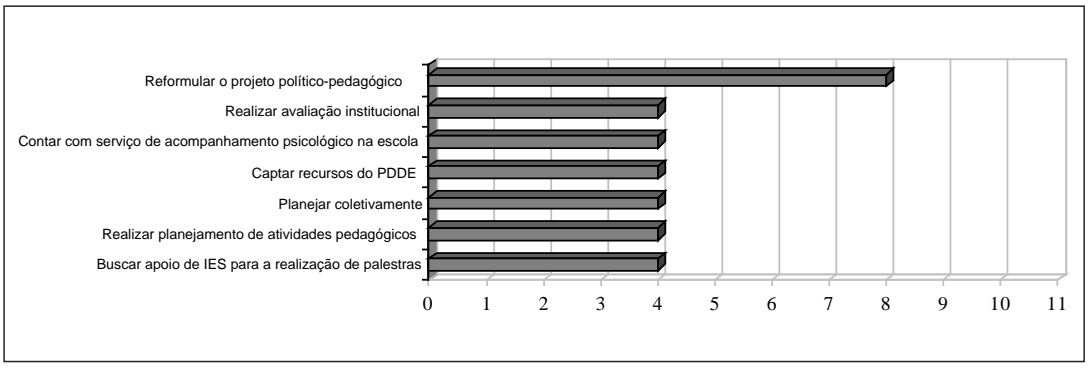

Fonte: organizado pelos pesquisadores com base nos questionários.

Gráfico 13 - Ação Relacionada à Formação dos Profissionais da Educação Básica - mencionada por mais de $20 \%$ dos gestores das escolas pesquisadas

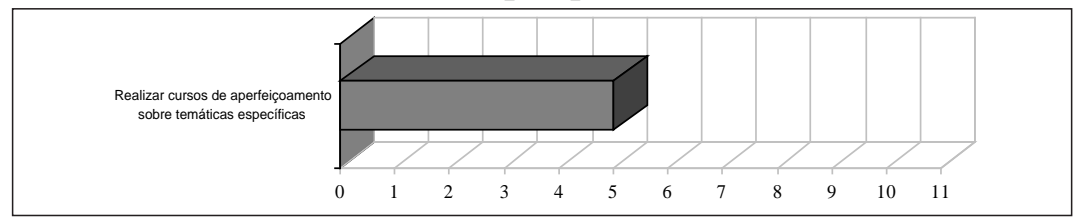

Fonte: organizado pelos pesquisadores com base em questionários.

Gráfico 14 - Ações Relacionadas às Práticas Pedagógicas - mencionadas por mais de $20 \%$ dos gestores das escolas pesquisadas

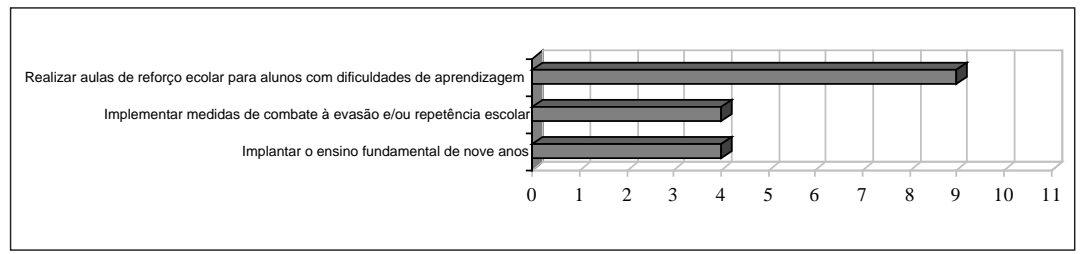

Fonte: organizado pelos pesquisadores com base nos questionários.

Ainda que a maior recorrência de ações e estratégias atinentes à infraestrutura escolar (condições físicas e recursos pedagógicos) possa ser vista sem maior estranhamento, esse é sempre um dado preocupante, dadas as consequências da falta de condições concretas para o trabalho educativo, independente do ângulo de análise. Ao fim e ao cabo, é sabido que uma leitura atenta e responsável deságua invariavelmente na relação direta entre condições objetivas para a realização do trabalho educativo e qualidade da educação, relação essa que as indicações das escolas pesquisadas parecem reforçar.

Nos eixos da dimensão de infraestrutura e nos demais, é possível perceber que há sintonia entre ações e estratégias e os problemas mais 
frequentes que as escolas se propõem a enfrentar visando à melhoria da qualidade da educação. Consoante informaram, na Dimensão 2 (gestão escolar) sobressaem ações focalizadas no planejamento e, na Dimensão 4, na organização didático-pedagógica. A exceção é a ação indicada no Gráfico 13, relativa à formação dos profissionais da educação básica, cujo eixo correspondente - formação continuada - não foi referido por mais de $20 \%$ dos gestores.

Se esses dados expressam o quadro geral das ações e estratégias traçadas visando à melhoria da qualidade nas escolas aqui referidas, há que se considerar singularidades entre essas ações e estratégias, preservado o propósito de realçar as recorrências e o de verificar traços comuns entre medidas operadas e resultados alcançados.

Para esse detalhamento, as escolas foram agrupadas em dois conjuntos. O primeiro composto por aquelas que indicaram as ações e estratégias em até duas dimensões e, o segundo, por escolas que as indicaram em três ou quatro dimensões ${ }^{7}$. Nesse exercício, buscamos relacionar, sempre que possível, as ações e estratégias de cada escola com a síntese de resultados (parciais ou finais) que, na voz dos gestores, seriam sinalizadores de conquistas visando à qualidade e com as variações nos índices e indicadores oficiais do biênio 2009-2011. O Quadro 1 traz os dados das escolas do primeiro conjunto.

\section{Quadro 1 - Ações e Estratégias, Síntese de Resultados e Variação nos Índices e Indicadores Oficiais (2009-2011) - escolas com ações e estratégias em até duas dimensões}

\begin{tabular}{|c|c|c|c|c|c|c|c|c|}
\hline 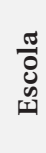 & \multicolumn{2}{|c|}{$\begin{array}{c}\text { Ações e estratégias } \\
\text { traçadas } \\
\text { (Dimensão/ } \\
\text { Descrição) }\end{array}$} & $\begin{array}{l}\text { Síntese de } \\
\text { resultados } \\
\text { (parciais } \\
\text { ou finais) } \\
\text { alcançados }\end{array}$ & \multicolumn{5}{|c|}{$\begin{array}{c}\text { Variações no Ideb, indicador } \\
\text { de Rendimento }(\mathrm{P}) \text { e } \\
\text { Prova Brasil } \\
(2009-2011)\end{array}$} \\
\hline \multirow{6}{*}{3} & \multirow{5}{*}{ I } & \multirow{5}{*}{$\begin{array}{l}\text { Adquirir material } \\
\text { didático- } \\
\text { pedagógico } \\
\text { Ampliar o acervo } \\
\text { da biblioteca } \\
\text { Adquirir } \\
\text { mobiliário } \\
\text { escolar } \\
\text { Adquirir } \\
\text { equipamentos/ } \\
\text { eletrodomésticos }\end{array}$} & \multirow{6}{*}{$\begin{array}{l}\text { [Não } \\
\text { declarou] }\end{array}$} & \multicolumn{2}{|c|}{ Ideb } & (D) & Pro & Brasil \\
\hline & & & & \multirow{2}{*}{ AI } & \multirow{2}{*}{$(*)$} & \multirow{2}{*}{-} & $M$ & - \\
\hline & & & & & & & LP & - \\
\hline & & & & \multirow[t]{2}{*}{$\mathrm{AF}$} & \multirow[t]{2}{*}{$-0,2$} & \multirow[t]{2}{*}{$-0,02$} & M & $-3,36$ \\
\hline & & & & & & & LP & $-4,90$ \\
\hline & IV & $\begin{array}{l}\text { Realizar aulas } \\
\text { de reforço para } \\
\text { alunos com } \\
\text { dificuldades de } \\
\text { aprendizagem }\end{array}$ & & & & & & \\
\hline
\end{tabular}


Qualidade na Educação Básica

\begin{tabular}{|c|c|c|c|c|c|c|c|c|}
\hline \multirow{7}{*}{5} & \multirow{6}{*}{ I } & \multirow{6}{*}{$\begin{array}{l}\text { Adquirir material } \\
\text { didático- } \\
\text { pedagógico } \\
\text { Ampliar o acervo } \\
\text { da biblioteca } \\
\text { Adquirir } \\
\text { mobiliário } \\
\text { escolar } \\
\text { Reformar o } \\
\text { prédio escolar } \\
\text { ou dependências } \\
\text { específicas } \\
\text { Ampliar a } \\
\text { estrutura física } \\
\text { Instalar } \\
\text { laboratório de } \\
\text { informática }\end{array}$} & \multirow{7}{*}{ [Não } & \multicolumn{2}{|c|}{ Ideb } & \multirow{3}{*}{$\frac{(\mathrm{P})}{-}$} & Pro & Brasil \\
\hline & & & & \multirow[t]{2}{*}{$\mathrm{AI}$} & \multirow[t]{2}{*}{$\left({ }^{*}\right)$} & & $\mathrm{M}$ & - \\
\hline & & & & & & & LP & - \\
\hline & & & & $\mathrm{AF}$ & $(* *)$ & - & M & - \\
\hline & & & & & & & LP & - \\
\hline & & & & & & & & \\
\hline & II & $\begin{array}{l}\text { Reformular o PPP } \\
\text { Contar com } \\
\text { serviço de } \\
\text { acompanha- } \\
\text { mento psicoló- } \\
\text { gico }\end{array}$ & & & & & & \\
\hline \multirow{5}{*}{6} & \multirow{5}{*}{ I } & \multirow{5}{*}{$\begin{array}{l}\text { Adquirir } \\
\text { material didático } \\
\text { apostilado }\end{array}$} & \multirow{5}{*}{$\begin{array}{l}\text { Atendimento } \\
\text { das } \\
\text { necessidades } \\
\text { dos professores } \\
\text { e alunos. } \\
\text { Melhoria da } \\
\text { qualidade } \\
\text { do ensino e } \\
\text { aprendizagem }\end{array}$} & \multicolumn{2}{|c|}{ Ideb } & (P) & \multicolumn{2}{|c|}{ Prova Brasil } \\
\hline & & & & $\mathrm{AI}$ & $+0,7$ & $+0,01$ & $\mathrm{M}$ & $+23,24$ \\
\hline & & & & & & & LP & $+11,76$ \\
\hline & & & & $\mathrm{AF}$ & $(* *)$ & - & $\mathrm{M}$ & - \\
\hline & & & & & & & LP & - \\
\hline \multirow{8}{*}{8} & \multirow{7}{*}{ I } & \multirow{7}{*}{$\begin{array}{l}\text { Adquirir material } \\
\text { didático- } \\
\text { pedagógico } \\
\text { Adquirir } \\
\text { material didático } \\
\text { apostilado } \\
\text { Ampliar a } \\
\text { estrutura física } \\
\text { Adquirir } \\
\text { equipamentos/ } \\
\text { eletrodomésticos } \\
\text { Instalar } \\
\text { laboratório de } \\
\text { informática }\end{array}$} & \multirow{8}{*}{$\begin{array}{l}\text { Atendimento às } \\
\text { necessidades da } \\
\text { escola, melhora } \\
\text { na organização } \\
\text { do ambiente } \\
\text { escolar e na } \\
\text { aprendizagem } \\
\text { dos alunos. }\end{array}$} & & & & & \\
\hline & & & & \multicolumn{2}{|c|}{ Ideb } & (P) & \multicolumn{2}{|c|}{ Prova Brasil } \\
\hline & & & & \multirow[t]{2}{*}{$\mathrm{AI}$} & \multirow[t]{2}{*}{$+0,7$} & \multirow[t]{2}{*}{$+0,04$} & $\mathrm{M}$ & $+12,00$ \\
\hline & & & & & & & LP & $+13,61$ \\
\hline & & & & \multirow[t]{4}{*}{$\mathrm{AF}$} & \multirow[t]{2}{*}{$(* *)$} & \multirow[t]{2}{*}{ - } & $\mathrm{M}$ & - \\
\hline & & & & & & & $\overline{\mathrm{LP}}$ & - \\
\hline & & & & & & & & \\
\hline & II & $\begin{array}{l}\text { Realizar } \\
\text { avaliação } \\
\text { institucional } \\
\end{array}$ & & & & & & \\
\hline \multirow{5}{*}{11} & \multirow{5}{*}{ II } & \multirow{5}{*}{$\begin{array}{l}\text { Reformular o PPP } \\
\text { Captar recursos } \\
\text { do PDDE } \\
\text { Realizar } \\
\text { planejamento } \\
\text { de atividades } \\
\text { pedagógicas }\end{array}$} & \multirow{5}{*}{$\begin{array}{l}\text { [Não } \\
\text { declarou] }\end{array}$} & & $\overline{e b}$ & (P) & Pro & Brasil \\
\hline & & & & AI & $+0,1$ & $+0,06$ & $\mathrm{M}$ & $+4,21$ \\
\hline & & & & & & & LP & $-17,46$ \\
\hline & & & & $\mathrm{AF}$ & $+1,2$ & $+0,2$ & $\mathrm{M}$ & $-12,78$ \\
\hline & & & & & & & LP & $+22,45$ \\
\hline
\end{tabular}




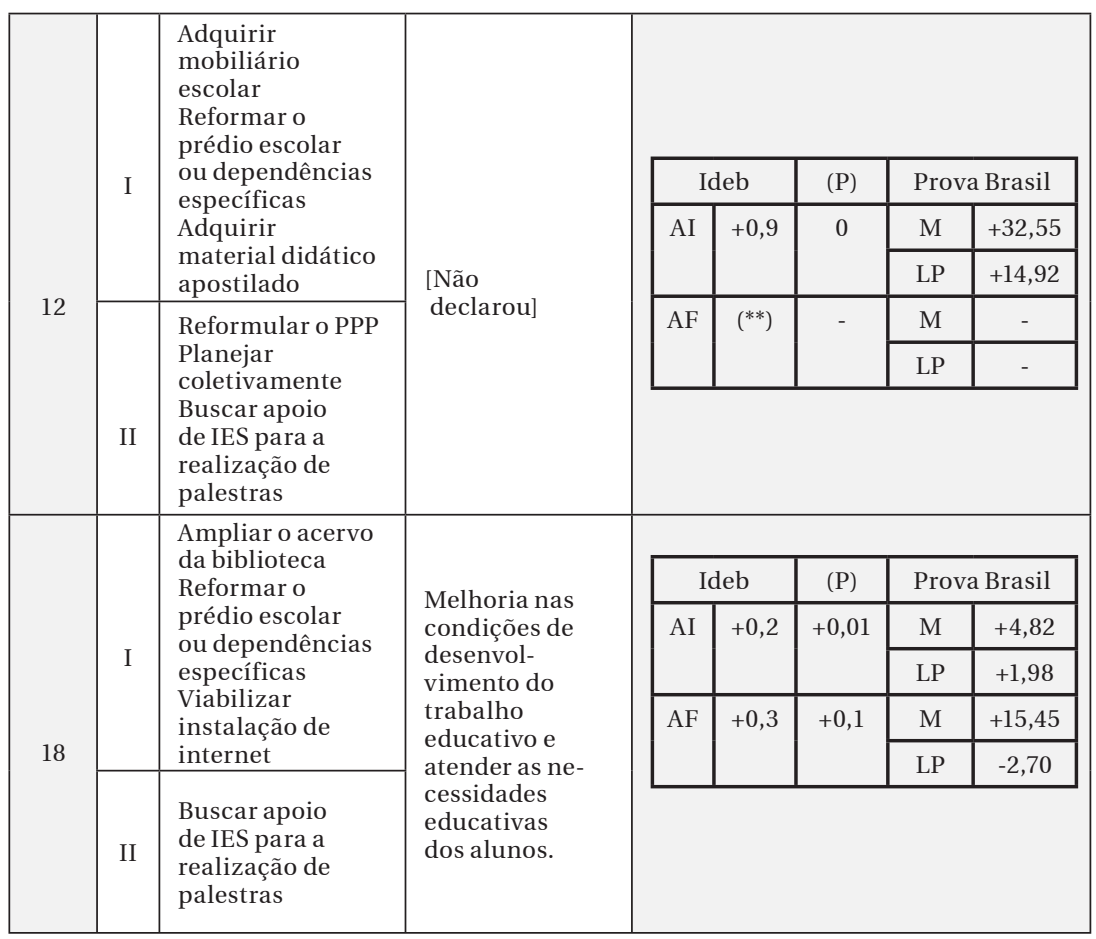

$\left({ }^{*}\right)$ Em 2009 e/ou 2011 não houve registro de Ideb da Escola

(**) A Escola não oferece essa etapa do ensino fundamental.

Fonte: organizado pelos pesquisadores com base em questionários.

Como se pode observar, todas as escolas do primeiro conjunto indicaram ações e estratégias na Dimensão 1 sendo também nesta que se verifica maior convergência de ações entre escolas ainda que não envolvendo todo o conjunto. A Dimensão 2 foi a segunda mais referida pelas escolas, porém as ações e estratégias abarcadas nessa dimensão são menos frequentes quando comparadas às da primeira dimensão.

Há grande sintonia entre as escolas quanto aos resultados alcançados e as ações implementadas. Entre as que os declararam, a melhoria nas condições de desenvolvimento do trabalho educativo é ponto comum, assim como houve uma variação positiva no Ideb (2009-2011) ainda que não em relação às variações na pontuação da Prova Brasil.

É no subconjunto composto pelas escolas 6, 8 e 12 que o cruzamento de ações e estratégias, resultados alcançados (neste caso as escolas 6 e 8) e variação dos índices e indicadores educacionais, revela um traço comum acentuado, a saber: as três escolas que oferecem somente os anos iniciais do ensino fundamental têm em comum uma ação da Dimensão 1 - Adquirir material didático apostilado. Em comum, também apontam como resultados o atendimento às necessidades (professor/ escola) e a melhoria na aprendizagem dos alunos. Essas mesmas esco-

Educação \& Realidade, Porto Alegre, v. 39, n. 2, p. 359-390, abr./jun. 2014. 
las registraram as três maiores variações positivas no Ideb (2009-2011) e nas notas da Prova Brasil nas duas áreas avaliadas (Língua Portuguesa e Matemática). Em relação aos indicadores de rendimento (taxas de aprovação), foram registradas as menores variações (positivas).

Vejamos agora o que informam os dados do Quadro 2, relativos às escolas cujas ações estão presentes em três ou quatro dimensões:

Quadro 2 - Ações e Estratégias, Síntese de Resultados e Variação nos Índices e Indicadores Oficiais (2009-2011) - escolas com ações e estratégias em mais de duas dimensões

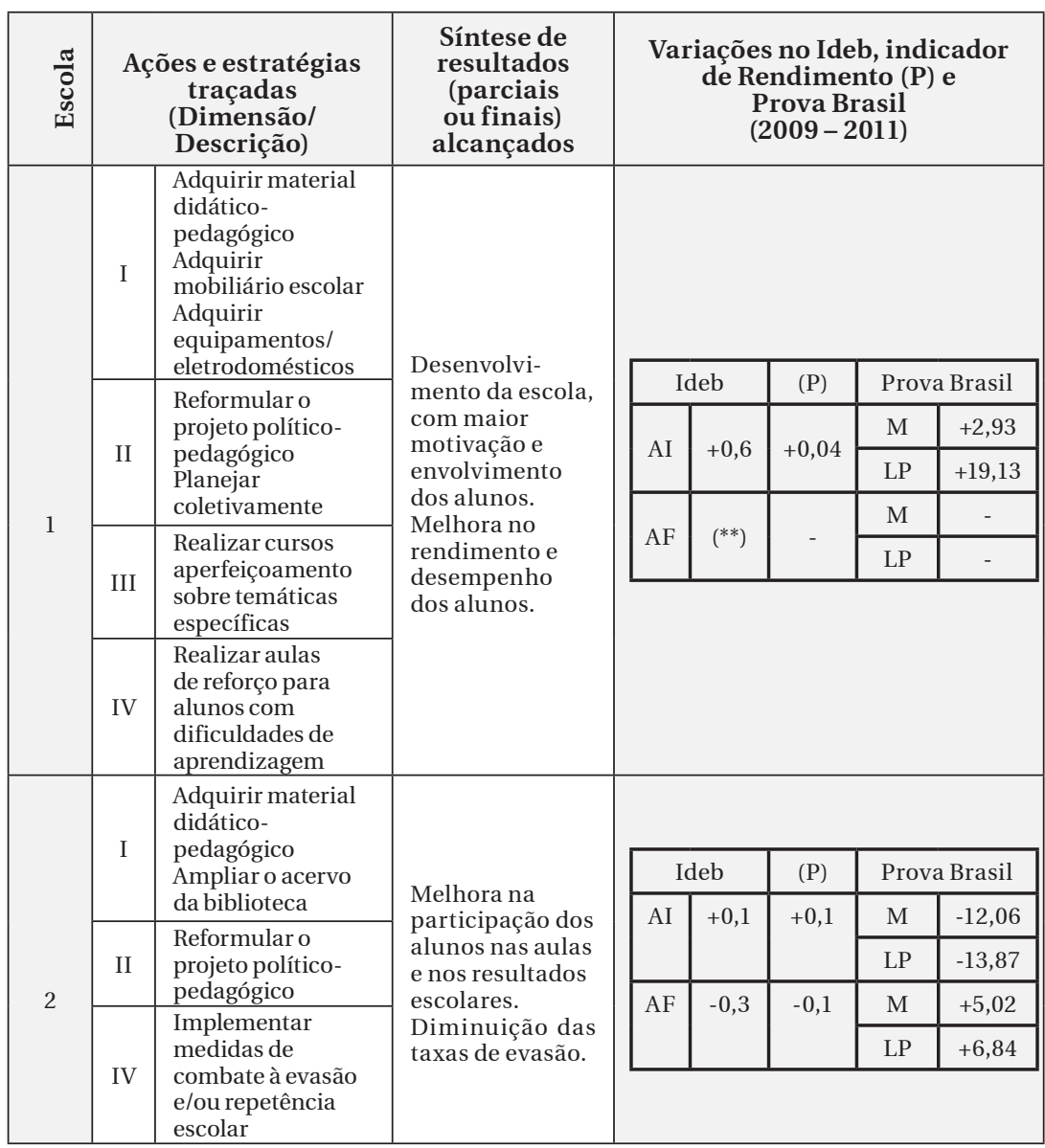


Nardi; Schneider; Rios

\begin{tabular}{|c|c|c|c|c|c|c|c|c|}
\hline \multirow{8}{*}{4} & \multirow[t]{3}{*}{ I } & \multirow[t]{3}{*}{$\begin{array}{l}\text { Adquirir material } \\
\text { didático-pedagógico } \\
\text { Ampliar o acervo da } \\
\text { biblioteca } \\
\text { Reformaro } \\
\text { prédio escolar } \\
\text { ou dependências } \\
\text { específicas } \\
\text { Adquirir material } \\
\text { didático apostilado } \\
\text { Viabilizar instalação } \\
\text { deinternet }\end{array}$} & \multirow{8}{*}{$\begin{array}{l}\text { Ampliação do } \\
\text { envolvimento } \\
\text { dos alunos e } \\
\text { professores com } \\
\text { a escola e da } \\
\text { participação dos } \\
\text { pais. } \\
\text { Melhora nas } \\
\text { condições de } \\
\text { acesso dos } \\
\text { alunos ao } \\
\text { conhecimento } \\
\text { e na } \\
\text { aprendizagem. }\end{array}$} & \multirow{2}{*}{\multicolumn{2}{|c|}{ Ideb }} & \multirow{4}{*}{$\begin{array}{r}(\mathrm{P}) \\
+0,03\end{array}$} & \multirow{2}{*}{\multicolumn{2}{|c|}{ Prova Brasil }} \\
\hline & & & & & & & & \\
\hline & & & & \multirow{2}{*}{ AI } & \multirow{2}{*}{$+0,6$} & & M & $+20,33$ \\
\hline & \multirow[b]{4}{*}{ II } & \multirow{4}{*}{$\begin{array}{l}\text { Reformularo } \\
\text { projeto político- } \\
\text { pedagógico } \\
\text { Contar com } \\
\text { serviço de } \\
\text { acompanhamento } \\
\text { psicológico } \\
\text { Realizar } \\
\text { planejamento } \\
\text { de atividades } \\
\text { pedagógicas }\end{array}$} & & & & & LP & $+15,54$ \\
\hline & & & & \multirow{4}{*}{$\mathrm{AF}$} & \multirow{2}{*}{$(* *)$} & \multirow{2}{*}{-} & $\mathrm{M}$ & - \\
\hline & & & & & & & LP & - \\
\hline & & & & & & & & \\
\hline & IV & $\begin{array}{l}\text { Realizar aulas de } \\
\text { reforço para alunos } \\
\text { com dificuldades } \\
\text { de aprendizagem }\end{array}$ & & & & & & \\
\hline \multirow{8}{*}{7} & I & $\begin{array}{l}\text { Adquirirmaterial } \\
\text { didático-pedagógico } \\
\text { Ampliaroacervoda } \\
\text { biblioteca } \\
\text { Adquirirmobiliário } \\
\text { escolar } \\
\text { Adquirirmaterial } \\
\text { didáticoapostilado } \\
\text { Viabilizarinstalaçãode } \\
\text { internet } \\
\text { Adquirir } \\
\text { equipamentos/ } \\
\text { eletrodomésticos } \\
\end{array}$ & \multirow{8}{*}{ [Não declarou] } & & & & & \\
\hline & \multirow{5}{*}{ II } & \multirow{5}{*}{$\begin{array}{l}\text { Reformularoprojeto } \\
\text { político-pedagógico } \\
\text { Realizaravaliação } \\
\text { institucional } \\
\text { Realizar } \\
\text { planejamento } \\
\text { deatividades } \\
\text { pedagógicas }\end{array}$} & & \multicolumn{2}{|c|}{ Ideb } & (P) & \multicolumn{2}{|c|}{ Prova Brasil } \\
\hline & & & & \multirow[t]{2}{*}{ AI } & \multirow[t]{2}{*}{$+0,8$} & \multirow[t]{2}{*}{$+0,02$} & M & $+18,88$ \\
\hline & & & & & & & LP & $+22,59$ \\
\hline & & & & \multirow[t]{4}{*}{$\mathrm{AF}$} & \multirow[t]{2}{*}{0} & \multirow[t]{2}{*}{$+0,06$} & M & $-1,08$ \\
\hline & & & & & & & LP & $-22,00$ \\
\hline & III & $\begin{array}{l}\text { Realizarcursos } \\
\text { aperfeiçoamento } \\
\text { sobretemáticas } \\
\text { específicas }\end{array}$ & & & & & & \\
\hline & IV & $\begin{array}{l}\text { Realizaraulasde } \\
\text { reforçoparaalunos } \\
\text { comdificuldadesde } \\
\text { aprendizagem } \\
\text { Implementarmedidas } \\
\text { decombateàevasãoe/ } \\
\text { ourepetênciaescolar } \\
\text { Implantaroensino } \\
\text { fundamentaldenove } \\
\text { anos } \\
\end{array}$ & & & & & & \\
\hline
\end{tabular}

Educação \& Realidade, Porto Alegre, v. 39, n. 2, p. 359-390, abr./jun. 2014.

Disponível em: <http://www.ufrgs.br/edu_realidade> 


\begin{tabular}{|c|c|c|c|c|c|c|c|c|}
\hline \multirow{8}{*}{9} & I & $\begin{array}{l}\text { Adquirir material } \\
\text { didático- } \\
\text { pedagógico } \\
\text { Ampliar o acervo } \\
\text { da biblioteca } \\
\text { Adquirir } \\
\text { mobiliário escolar } \\
\text { Viabilizar } \\
\text { instalação de } \\
\text { internet } \\
\text { Ampliar a } \\
\text { estrutura física }\end{array}$ & \multirow{8}{*}{$\begin{array}{l}\text { Ampliação do } \\
\text { interesse dos } \\
\text { alunos pelo } \\
\text { conhecimento } \\
\text { e melhora no } \\
\text { seu rendimento. } \\
\text { Melhoria da } \\
\text { qualidade } \\
\text { do ensino e } \\
\text { fortalecimento } \\
\text { das relações da } \\
\text { escola com a } \\
\text { comunidade. }\end{array}$} & & & & & \\
\hline & \multirow{4}{*}{ II } & \multirow{4}{*}{$\begin{array}{l}\text { Realizar } \\
\text { planejamento } \\
\text { de atividades } \\
\text { pedagógicas } \\
\text { Buscar apoio } \\
\text { de IES para a } \\
\text { realização de } \\
\text { palestras }\end{array}$} & & & & & & \\
\hline & & & & \multicolumn{2}{|c|}{ Ideb } & $(\mathrm{P})$ & \multicolumn{2}{|c|}{ Prova Brasil } \\
\hline & & & & AI & $+1,3$ & 0 & $\mathrm{M}$ & $+46,62$ \\
\hline & & & & & & & LP & $+27,91$ \\
\hline & & Realizar cursos & & $\mathrm{AF}$ & $\left({ }^{*}\right)$ & - & M & - \\
\hline & III & & & & & & LP & - \\
\hline & IV & $\begin{array}{l}\text { Realizar aulas } \\
\text { de reforço para } \\
\text { alunos com } \\
\text { dificuldades de } \\
\text { aprendizagem } \\
\text { Implementar } \\
\text { medidas de } \\
\text { combate à evasão } \\
\text { e/ou repetência } \\
\text { escolar } \\
\text { Implantar o ensino } \\
\text { fundamental de } \\
\text { nove anos }\end{array}$ & & & & & & \\
\hline \multirow{8}{*}{10} & \multirow{4}{*}{ I } & \multirow{4}{*}{$\begin{array}{l}\text { Adquirir material } \\
\text { didático- } \\
\text { pedagógico } \\
\text { Ampliar o acervo } \\
\text { da biblioteca } \\
\text { Reformar o } \\
\text { prédio escolar } \\
\text { ou dependências } \\
\text { específicas } \\
\text { Viabilizar } \\
\text { instalação de } \\
\text { internet }\end{array}$} & \multirow{8}{*}{$\begin{array}{l}\text { Melhoria das } \\
\text { condições de } \\
\text { trabalho dos } \\
\text { professores e } \\
\text { de resposta às } \\
\text { necessidades } \\
\text { dos alunos, } \\
\text { de modo a } \\
\text { favorecer a } \\
\text { aprendizagem. }\end{array}$} & & & & & \\
\hline & & & & \multicolumn{2}{|c|}{ Ideb } & (P) & \multicolumn{2}{|c|}{ Prova Brasil } \\
\hline & & & & AI & $+0,7$ & $-0,04$ & $\mathrm{M}$ & $+21,89$ \\
\hline & & & & & & & LP & $+24,13$ \\
\hline & & Contar com & & $\mathrm{AF}$ & $+0,3$ & $+0,12$ & $\mathrm{M}$ & $-3,30$ \\
\hline & II & $\begin{array}{l}\text { serviço de } \\
\text { acompanhamento }\end{array}$ & & & & & LP & $-12,03$ \\
\hline & & psicológico & & & & & & \\
\hline & IV & $\begin{array}{l}\text { Realizar aulas } \\
\text { de reforço para } \\
\text { alunos com } \\
\text { dificuldades de } \\
\text { aprendizagem }\end{array}$ & & & & & & \\
\hline
\end{tabular}


Nardi; Schneider; Rios

\begin{tabular}{|c|c|c|c|c|c|c|c|c|}
\hline & & $\begin{array}{l}\text { Ampliar o acervo } \\
\text { da biblioteca } \\
\text { Adquirir } \\
\text { mobiliário escolar } \\
\text { Reformar o }\end{array}$ & & & & & & \\
\hline & $\mathrm{I}$ & prédio escolar & & & eb & (P) & Pro & Brasil \\
\hline & & específicas & & AI & $(*)$ & 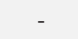 & M & - \\
\hline & & $\begin{array}{l}\text { Ampliar a } \\
\text { estrutura física }\end{array}$ & Melhoria nas & & & & LP & - \\
\hline 13 & & Buscar apoio & $\begin{array}{l}\text { condições de } \\
\text { atendimento aos }\end{array}$ & $\mathrm{AF}$ & $-0,2$ & $-0,09$ & M & $+15,62$ \\
\hline & II & realização de & alunos. & & & & LP & $+0,95$ \\
\hline & & palestras & & & & & & \\
\hline & III & $\begin{array}{l}\text { Realizar cursos } \\
\text { aperfeiçoamento } \\
\text { sobre temáticas } \\
\text { específicas }\end{array}$ & & & & & & \\
\hline \multirow{9}{*}{14} & $\mathrm{I}$ & $\begin{array}{l}\text { Adquirir material } \\
\text { didático- } \\
\text { pedagógico } \\
\text { Ampliar o acervo } \\
\text { da biblioteca } \\
\text { Ampliar a } \\
\text { estrutura física } \\
\text { Instalar } \\
\text { laboratório de } \\
\text { informática }\end{array}$ & \multirow{9}{*}{$\begin{array}{l}\text { Melhoria nas } \\
\text { condições } \\
\text { de trabalho } \\
\text { escolar, na } \\
\text { aprendizagem } \\
\text { dos e no } \\
\text { desempenho } \\
\text { dos alunos nas } \\
\text { avaliações. } \\
\text { Diminuição da } \\
\text { repetência e } \\
\text { fortalecimento } \\
\text { da relação da } \\
\text { escola com as } \\
\text { famílias. }\end{array}$} & & & & & \\
\hline & \multirow{5}{*}{ II } & \multirow{5}{*}{$\begin{array}{l}\text { Reformularo } \\
\text { projeto político- } \\
\text { pedagógico } \\
\text { Realizar avaliação } \\
\text { institucional } \\
\text { Contar com } \\
\text { serviço de } \\
\text { acompanhamento } \\
\text { psicológico } \\
\text { Captar recursos do } \\
\text { PDDE } \\
\text { Planejar } \\
\text { coletivamente } \\
\end{array}$} & & & & & & \\
\hline & & & & \multicolumn{2}{|c|}{ Ideb } & $(\mathrm{P})$ & \multicolumn{2}{|c|}{ Prova Brasil } \\
\hline & & & & \multirow[t]{2}{*}{ AI } & \multirow[t]{2}{*}{$(*)$} & \multirow[t]{2}{*}{-} & $\mathrm{M}$ & - \\
\hline & & & & & & & LP & - \\
\hline & & & & \multirow[t]{2}{*}{$\mathrm{AF}$} & \multirow[t]{2}{*}{$(* *)$} & \multirow[t]{2}{*}{-} & M & - \\
\hline & & $\begin{array}{l}\text { Realizar cursos } \\
\text { aperfeicoamento }\end{array}$ & & & & & LP & - \\
\hline & III & $\begin{array}{l}\text { sobre temáticas } \\
\text { específicas }\end{array}$ & & & & & & \\
\hline & IV & $\begin{array}{l}\text { Realizar aulas } \\
\text { de reforço para } \\
\text { alunos com } \\
\text { dificuldades de } \\
\text { aprendizagem } \\
\text { Implementar } \\
\text { medidas de } \\
\text { combate à evasão } \\
\text { e/ou repetência } \\
\text { escolar } \\
\text { Implantar o ensino } \\
\text { fundamental de } \\
\text { nove anos }\end{array}$ & & & & & & \\
\hline
\end{tabular}

Educação \& Realidade, Porto Alegre, v. 39, n. 2, p. 359-390, abr./jun. 2014.

Disponível em: <http://www.ufrgs.br/edu_realidade> 


\begin{tabular}{|c|c|c|c|c|c|c|c|c|}
\hline \multirow{8}{*}{15} & \multirow[t]{4}{*}{ I } & \multirow{4}{*}{$\begin{array}{l}\text { Adquirir } \\
\text { mobiliário escolar } \\
\text { Reformar o } \\
\text { prédio escolar } \\
\text { ou dependências } \\
\text { específicas } \\
\text { Adquirir } \\
\text { material didático } \\
\text { apostilado } \\
\text { Viabilizar } \\
\text { instalação de } \\
\text { internet } \\
\text { Adquirir } \\
\text { equipamentos/ } \\
\text { eletrodomésticos }\end{array}$} & \multirow{8}{*}{$\begin{array}{l}\text { Viabilização de } \\
\text { condições básica } \\
\text { para o trabalho } \\
\text { educativo da } \\
\text { escola. Melhoria } \\
\text { na qualidade } \\
\text { dos processos } \\
\text { de ensino e } \\
\text { aprendizagem, } \\
\text { com maior } \\
\text { motivação e } \\
\text { desenvolvi- } \\
\text { mento do senso } \\
\text { crítico dos } \\
\text { alunos. } \\
\text { Diminuição } \\
\text { dos índices } \\
\text { de evasão e } \\
\text { repetência } \\
\text { escolar. }\end{array}$} & \multirow{2}{*}{\multicolumn{2}{|c|}{ Ideb }} & & & \\
\hline & & & & & & $(\mathrm{P})$ & \multicolumn{2}{|c|}{ Prova Brasil } \\
\hline & & & & \multirow[t]{2}{*}{$\mathrm{AI}$} & \multirow[t]{2}{*}{$+0,5$} & \multirow[t]{2}{*}{$-0,07$} & M & $+21,08$ \\
\hline & & & & & & & LP & $+27,23$ \\
\hline & \multirow{3}{*}{ II } & \multirow{3}{*}{$\begin{array}{l}\text { Realizar avaliação } \\
\text { institucional } \\
\text { Captar recursos do } \\
\text { PDDE } \\
\text { Planejar } \\
\text { coletivamente } \\
\end{array}$} & & \multirow[t]{4}{*}{$\mathrm{AF}$} & \multirow[t]{2}{*}{$+1,7$} & \multirow[t]{2}{*}{$+0,07$} & $\mathrm{M}$ & $+50,47$ \\
\hline & & & & & & & LP & $+57,39$ \\
\hline & & & & & & & & \\
\hline & IV & $\begin{array}{l}\text { Realizar aulas } \\
\text { de reforço para } \\
\text { alunos com } \\
\text { dificuldades de } \\
\text { aprendizagem } \\
\text { Implantar o ensino } \\
\text { fundamental de } \\
\text { nove anos }\end{array}$ & & & & & & \\
\hline \multirow{8}{*}{16} & \multirow{5}{*}{ I } & \multirow{5}{*}{$\begin{array}{l}\text { Adquirir material } \\
\text { didático- } \\
\text { pedagógico } \\
\text { Adquirir } \\
\text { mobiliário escolar } \\
\text { Reformar o } \\
\text { prédio escolar } \\
\text { ou dependências } \\
\text { específicas } \\
\text { Ampliar a } \\
\text { estrutura física } \\
\text { Instalar } \\
\text { laboratório de } \\
\text { informática } \\
\end{array}$} & \multirow{8}{*}{$\begin{array}{l}\text { Melhoria nas } \\
\text { condições de } \\
\text { trabalho do } \\
\text { professor e } \\
\text { no ambiente } \\
\text { escolar, } \\
\text { tornando-o } \\
\text { mais acolhedor. } \\
\text { Melhoria no } \\
\text { planejamento } \\
\text { escolar e maior } \\
\text { motivação } \\
\text { dos alunos. } \\
\text { Melhoria na } \\
\text { aprendizagem e } \\
\text { diminuição da } \\
\text { repetência. }\end{array}$} & & & & & \\
\hline & & & & \multicolumn{2}{|c|}{ Ideb } & (P) & \multicolumn{2}{|c|}{ Prova Brasil } \\
\hline & & & & \multirow{2}{*}{ AI } & \multirow{2}{*}{$+1,1$} & \multirow{2}{*}{$+0,05$} & $\mathrm{M}$ & $+19,79$ \\
\hline & & & & & & & LP & $+25,15$ \\
\hline & & & & \multirow{2}{*}{$\mathrm{AF}$} & \multirow{2}{*}{$+1,6$} & \multirow{2}{*}{$+0,21$} & $\mathrm{M}$ & $+10,34$ \\
\hline & U & Captar recursos do & & & & & LP & $+27,51$ \\
\hline & 11 & PDDE & & & & & & \\
\hline & IV & $\begin{array}{l}\text { Realizar aulas } \\
\text { de reforço para } \\
\text { alunos com } \\
\text { dificuldades de } \\
\text { aprendizagem }\end{array}$ & & & & & & \\
\hline
\end{tabular}

(*) Em 2009 e/ou 2011 não houve registro de Ideb da Escola

(**) A Escola não oferece essa etapa do ensino fundamental.

Fonte: organizado pelos pesquisadores com base em questionários.

Os dados do Quadro 2 evidenciam que, a exemplo das escolas do primeiro conjunto, todas as do segundo também investiram em ações e estratégias relacionadas à infraestrutura escolar. Contudo, nesse segundo conjunto a dimensão vem fortemente representada pelas ações de aquisição de material didático-pedagógico e de ampliação do acervo 
da biblioteca, citadas, respectivamente, por $80 \%$ e $70 \%$ das escolas. Com frequência equivalente, encontramos a realização de aulas de reforço para alunos com dificuldades de aprendizagem (70\% das escolas), ação da Dimensão IV (práticas pedagógicas) mobilizada por $90 \%$ das escolas.

Quais resultados declaram as escolas a partir das ações apontadas? De modo geral, despontam o alcance de um maior envolvimento, participação e/ou interesse dos alunos e a melhoria nas condições de trabalho na escola. Sobre esta, em vista da prevalência de ações relacionadas à infraestrutura escolar - não das que implicam condições de emprego dos professores -, fica evidente que o foco do resultado aludido recai nas condições objetivas de realização do processo de trabalho ${ }^{8}$.

Por meio do cruzamento de ações e estratégias, resultados alcançados e variação dos índices e indicadores educacionais, também neste segundo conjunto é possível perceber traços comuns, ainda que, inicialmente, sejam diferentes dos destacados no primeiro conjunto de escolas. No segundo conjunto, é nas escolas 1, 4, 9, 15 e 16 que esse cruzamento revela acentuados traços comuns: o primeiro deles é que em todas as escolas foi implementada a aquisição de material didático-pedagógico (Dimensão I) e a realização de aulas de reforço para alunos com dificuldades de aprendizagem (Dimensão IV). Em comum, também declaram como resultados a maior motivação e/ou envolvimento dos alunos nas atividades escolares e a melhora na aprendizagem e/ou rendimento/desempenho destes.

São essas mesmas escolas que registraram variações positivas no Ideb (as maiores estão neste segundo subconjunto) e nas notas da Prova Brasil em ambas as disciplinas, assim como pequenas variações (positivas) nos indicadores de rendimento 2009-2011. Nesse aspecto em específico, a escola 16 destoa das demais do subconjunto por ter registrado, nos anos finais, variação muito superior às registradas pelas demais.

Vale destacar, ainda, que nas duas escolas do subconjunto que oferecem os anos finais, as variações positivas do Ideb nessa etapa foram as melhores de todas as escolas pesquisadas.

Os resultados gerais nos permitem constatar que, quanto à recorrência de resultados entre as escolas pesquisadas, sobressai, nos dois conjuntos, a melhoria das condições para desenvolver o trabalho educativo. Além disso, a melhoria na aprendizagem dos alunos, realçada pelo primeiro conjunto de escolas, e o seu maior envolvimento, participação e interesse, reforçado pelo segundo conjunto, por serem considerados aspectos entrecruzados que enfocam a aprendizagem, podem aqui ser tomados como um mesmo resultado.

Constatamos, portanto, que a melhoria das condições da escola para o desenvolvimento do trabalho educativo é um resultado que, na visão daqueles que vivem o cotidiano das escolas, possui refinada relação, ainda que não exclusiva, com as ações afetas à infraestrutura escolar (Dimensão I), justamente a mais recorrentes entre as escolas e 
que também compreende o campo mais referido no apontamento de problemas a serem por elas enfrentados.

Já o resultado que enfoca ganhos na aprendizagem dos alunos, ainda que de diferentes ângulos possa ser associado a todas as dimensões, por razões que a nós parecem óbvias, remete especialmente às práticas pedagógicas (Dimensão IV). Como demonstrado, nessa dimensão sobressai, em frequência, a realização de aulas de reforço para alunos com dificuldades de aprendizagem, embora o eixo que comporta essa ação (organização didático-pedagógico) tenha sido o quarto mais referido no apontamento de problemas enfrentados pela escola.

Se, por um lado, ganha realce essa relação entre ações e resultados registrada pela maioria das escolas pesquisadas visando à melhoria da qualidade da educação, segundo o horizonte dos objetivos almejados por elas, por outro não é possível estender a sintonia dessa relação à melhora dos resultados oficiais alcançados pelas mesmas escolas no período investigado. Como procuramos demonstrar, traços fortemente comuns derivados do entrecruzamento entre ações e estratégias, resultados alcançados e variação dos índices e indicadores educacionais são verificados em dois subconjuntos específicos de escolas. De todo modo, é menor a distância entre as escolas do segundo subconjunto e as demais do conjunto a que pertencem quando comparada à das escolas do primeiro subconjunto e as demais do agrupamento.

Em suma, o cenário deslindado pela pesquisa nos dá indicativos de que, de um lado, as ações e estratégias abraçadas pelas escolas resultaram, segundo sua ótica, em melhorias capazes de repercutir na qualidade da educação. De outro, que é frágil o impacto do tipo de resposta, nos indicadores oficiais, oferecido por essas escolas por meio das ações e estratégias eleitas no contexto dos estímulos patrocinados pelas políticas em vigor, nomeadamente pela via da produção e ampla disseminação desses indicadores.

Embora o debate acerca dos motivos que ancoram a fragilidade desse impacto fuja ao alcance deste trabalho, é possível referir que esses indicativos constituem mostra de uma tensão entre meios (e quiçá opções) internos às escolas e expectativas externas a elas no tocante à produção de um ensino de qualidade, mesmo com certa permeabilidade das políticas recentes à abordagem da qualidade social da educação.

\section{Considerações Finais}

Atentos à emergência dos exames externos de avaliação de redes de ensino e escolas, que encontraram lastro nas políticas educacionais das últimas décadas, buscamos analisar no presente trabalho o enfoque conferido a ações e estratégias mais recorrentes em um conjunto de escolas catarinenses de ensino fundamental, traçadas após a divulgação do Ideb 2009 com o propósito declarado de melhorar a qualidade da educação. Como parte da análise, procuramos destacar traços comuns 
entre essas ações e estratégias, resultados alcançados e variações nos índices e indicadores oficiais no biênio 2009-2011.

Ao tempo em que indagamos acerca do projeto de qualidade em favor do qual ações e estratégias vêm sendo requeridas, buscamos problematizar as circunstâncias que concorrem para a determinação das prioridades para a escola e a apropriação, pelos sujeitos escolares, dos dados que oficialmente informam a qualidade da educação.

Ao considerar que gestores escolares têm sido chamados a propor medidas que possibilitem o alcance de melhores resultados educacionais, notadamente pelo Estado e pela mídia, que frequentemente põem em relevo descompassos entre necessidades e soluções, buscamos destacar tanto o desafio das escolas de corresponder a esta e a outras demandas e objetivos locais, como as próprias ações e estratégias por elas propostas e implementadas para o enfrentamento de problemas que julgam centrais.

Conforme buscarmos ressaltar, o que em geral apontam as escolas pesquisadas como problemas de maior expressão e o que propõem em termos de ações de estratégias, ainda que nem sempre com refinada sintonia, sinaliza, antes de tudo, a busca por condições objetivas para o trabalho educativo. Porém, não encontramos correspondência uniforme entre ações dessa natureza, mobilizada pela massiva maioria das escolas, e o alcance de melhores índices e indicadores oficiais, notadamente quando observados apenas resultados da Prova Brasil. Encontramos sim, melhor correspondência entre ações e estratégias e os resultados que os gestores declaram ter alcançado. Dentre estes, a melhoria na aprendizagem e no rendimento dos alunos ganharam expressivo espaço.

No entanto, visto do ângulo do sistema externo de avaliação, o desempenho das escolas pesquisadas, informado pela proficiência dos alunos em Matemática e Língua Portuguesa, ainda dista dos referenciais mínimos considerados apropriados. Preocupam tanto a baixa pontuação alcançada (especialmente nos anos finais do ensino fundamental) quanto a disparidade entre escolas que, em sua maioria, guardam características muito próximas. Portanto, a melhora alcançada no Ideb não foi, na maior parte dos casos, acompanhada de considerável melhora na proficiência dos alunos, diferente do que ocorreu com o indicador de rendimento, em vista do aumento das taxas de aprovação.

Como procuramos demonstrar, a melhor relação entre as ações e estratégias propostas, resultados alcançados pelas escolas e melhora nos índices e indicadores oficiais foi percebida em apenas dois subconjuntos de escolas que, entre si, diferenciam-se nas ações e estratégias propostas e se aproximam em termos de resultados alcançados e aumento nos índices e indicadores oficiais.

Embora possamos considerar a interveniência de vários fatores, é revelador o fato de, nas escolas em que ações traçadas compreenderam até duas das dimensões investigadas, a melhor relação vir associada à 
adoção de material pedagógico apostilado, com destaque ao alcance de melhores índices e indicadores educacionais. Como se sabe, a sistemas dessa natureza comumente vinculam-se outras ações, como formação continuada de professores e aportes no campo da gestão escolar, especialmente no campo pedagógico.

Ainda que a convergência de esforços e, portanto, do foco de ações e estratégias na melhoria dos indicadores oficiais não tenha sido pontualmente declarada pelos gestores, evidências como a identificada no primeiro subconjunto leva-nos a problematizar o sentido que pode assumir o planejamento e a dinâmica das escolas a partir da implantação do Ideb.

A confirmar-se a tendência de, a despeito do projeto educativo da escola, a meta central ser a de atender aos índices e indicadores oficiais, corre-se o risco de que os resultados tenham um fim em si mesmo, sem assegurar avanços efetivos na qualidade da educação. Por isso, avançar rumo à articulação entre os processos de autoavaliação institucional, avaliação externa e avaliação da aprendizagem, conforme propõem Freitas e outros (2011), parece-nos um caminho coerente na perspectiva da construção de uma educação de qualidade socialmente referenciada, para o que também é necessária a apropriação diagnóstica, pela escola, dos índices e indicadores educacionais oficiais.

Em um contexto que informa o reforço da posição do Ideb como principal referência no monitoramento da qualidade da educação básica brasileira, a despeito da complexidade de fatores e elementos que envolvem a qualidade enquanto produto histórico e social que reflete posicionamentos políticos e ideológicos (Barretto, 2001), a articulação aqui destacada representa, sem dúvida, um desafio a ser enfrentado.

Recebido em 09 de julho de 2013 Aprovado em 02 de março de 2014

\section{Notas}

10 termo é aqui empregado para referir exclusivamente o IDEB.

2 A esse respeito, ver Fernandes (2007).

3 O presente trabalho foi realizado com apoio do Programa Observatório da Educação, da Coordenação de Aperfeiçoamento de Pessoal de Nível Superior - CAPES/Brasil.

4 O termo, tomado de empréstimo de Azevedo (2011), designa um sistema de valores que integra a qualidade e seus parâmetros em cada sociedade.

5 Em termos de pontuação na Prova Brasil, a faixa considerada desejável corresponde aos dados sinalizados pelo Parecer CNE/CEB n. 8/2010 (Brasil, 2010a).

6 Os questionários foram elaborados pelos pesquisadores com o objetivo de captar propostas de ações e estratégias prioritárias, traçadas pelas escolas a cada período, considerando um conjunto de dimensões e eixos definidos com base nas dimensões e áreas eleitas pelo Ministério da Educação para a elaboração, 
pelos estados, municípios e o Distrito Federal, dos Planos de Ações Articuladas (PAR). Visaram obter informações de cada ação ou estratégia mediante descrição da iniciativa, do desenvolvimento, do período de realização, dos envolvidos e dos resultados alcançados.

7 Exceto a Escola 17, cujas ações e estratégias não foram informadas pelo gestor escolar na fase do levantamento.

8 Com base em Duarte (2011), enquanto as condições de emprego associam-se mais diretamente à carreira docente (salário, jornada de trabalho, contratos, tempos remunerados para o trabalho coletivo, formação continuada e outros), as condições objetivas do processo de trabalho têm a ver com as condições materiais, portanto, com o ambiente físico-organizacional no qual se desenvolve o trabalho docente (espaço físico, equipamentos, material de consumo e material didático, entre outros, que oferecem subsídios ao trabalho).

\section{Referências}

AZEVEDO, Janete Maria Lins de. Notas sobre a Análise da Gestão da Educação e da Qualidade do Ensino no Contexto das Políticas Educativas. Revista Brasileira de Política e Administração da Educação, Recife, v. 27, n. 3, p. 409-432, set./ dez. 2011.

BARRETTO, Elba Siqueira de Sá. A Avaliação na Educação Básica: entre dois modelos. Educação \& Sociedade, Campinas, ano XXII, n. 75, p. 48-66, ago. 2001.

BRASIL. Decreto n. 6.094, de 24 de abril de 2007. Dispõe sobre a implementação do Plano de Metas Compromisso Todos pela Educação, pela União Federal, em regime de colaboração com Municípios, Distrito Federal e Estados, e a participação das famílias e da comunidade, mediante programas e ações de assistência técnica e financeira, visando a mobilização social pela melhoria da qualidade da educação básica. Diário Oficial [da] República Federativa do Brasil, Poder Executivo, Brasília, DF, 25 abr. 2007. Seção 1, p. 5-6.

BRASIL. Parecer CNE/CEB n. 8, de 5 de maio de 2010. Estabelece normas para aplicação do inciso IX do artigo $4^{\circ}$ da Lei n. 9.394/96 (LDB), que trata dos padrões mínios de qualidade de ensino para a educação básica pública. 2010a. Disponível em: <http://portal.mec.gov.br/index.php?option=com_content\&vi ew=article\&id=15074\&Itemid=866>. Acesso em: 20 out. 2011. (Aguardando homologação).

BRASIL. Inep Divulga os Resultados do Ideb 2009: metas de qualidade foram cumpridas. Brasília, 5 jul. 2010b. Disponível em: <http://portal.inep.gov.br/ todas-noticias $>$. Acesso em: 8 out. 2011.

BRASIL. Resolução CNE/CEB 4, de 13 de julho de 2010. Define Diretrizes Curriculares Nacionais Gerais para a Educação Básica. Diário Oficial [da] República Federativa do Brasil, Poder Executivo, Brasília, DF, 14 jul. 2010c. Seção 1. P. 824-828.

BRASIL. Brasil Avança e Atinge as Metas Estabelecidas para Todas as Etapas. Brasília, 14 ago. 2012. Disponível em: <http://portal.inep.gov.br/todas-noticias>. Acesso em: 14 ago. 2012.

DOURADO, Luiz Fernandes; OLIVEIRA, João Ferreira de; SANTOS, Catarina de Almeida. A Qualidade da Educação: conceitos e definições. Textos para discussão. Série Documental, Brasília, v. 24, n. 22, p. 5-34, 2007.

DOURADO, Luiz Fernandes; OLIVEIRA, João Ferreira de. A Qualidade da Educação: perspectivas e desafios. Cadernos Cedes, Campinas, v. 29, n. 78, p. 201215, maio/ago. 2009.

Educação \& Realidade, Porto Alegre, v. 39, n. 2, p. 359-390, abr./jun. 2014.

Disponível em: <http://www.ufrgs.br/edu_realidade> 
Qualidade na Educação Básica

DUARTE, Adriana. Políticas Educacionais e o Trabalho Docente na Atualidade: tendências e contradições. In: OLIVEIRA, Dalila Andrade; DUARTE, Adriana (Org.). Políticas e Educação: regulação e conhecimento. Belo Horizonte: Fino Traço, 2011. P. 161-182.

FERNANDES, Reynaldo. Índice de Desenvolvimento da Educação Básica (Ideb). Brasília, DF: MEC/Inep, 2007.

FERNANDES, Reynaldo; GREMAUD, Amaury. Qualidade da Educação: avaliação, indicadores e metas. 2009. Disponível em: <http://www3.fgv.br/ibrecps/ rede/seminario/reynaldo_paper.pdf>. Acesso em: 20 mar. 2012.

FREITAS, Luiz Carlos et al. Avaliação Educacional: caminhando pela contramão. 3. ed. Petrópolis: Vozes, 2011.

OLIVEIRA, Romualdo Portela de; ARAUJO, Gilda Cardoso de. Qualidade do Ensino: uma nova dimensão da luta pelo direito à educação. Revista Brasileira de Educação, Rio de Janeiro, n. 28, p. 6-23, jan./abr. 2005.

PORTELA, Romualdo. Depoimento. Quarta-feira, 19 de novembro de 2008. Disponível em: <http://www.observatoriodaeducacao.org.br/index.php>. Acesso em: 03 jan. 2012.

SAVIANI, Dermeval. O Plano de Desenvolvimento da Educação: análise do projeto do MEC. Educação \& Sociedade, Campinas, v. 28, n. 100 - Especial, p. 12311255, out. 2007.

SOUSA, Sandra M. Zákia Lian. Possíveis Impactos das Políticas de Avaliação no Currículo Escolar. Cadernos de Pesquisa, São Paulo, n. 119, p. 175-190, jul. 2003.

SOUSA, Sandra M. Zákia Lian. Depoimento. Quarta-feira, 19 de novembro de 2008. Disponível em: <http://www.observatoriodaeducacao.org.br/index.php >. Acesso em: 03 jan. 2012.

Elton Luiz Nardi é doutor em Educação (UNISINOS), com Pós-Doutorado em Política Educativa pela Universidade do Minho - Portugal. Professor Titular do Programa de Pós-Graduação em Educação da Universidade do Oeste de Santa Catarina (UNOESC). Pesquisador do Grupo de Pesquisa Educação, Políticas Públicas e Cidadania da UNOESC.

E-mail: elton.nardi@unoesc.edu.br

Marilda Pasqual Schneider é doutora em Educação (UFSC), com Pós-Doutorado em Política Educativa pela Universidade do Minho - Portugal. Professora Titular do Programa de Pós-Graduação em Educação da Universidade do Oeste de Santa Catarina (UNOESC). Líder do Grupo de Pesquisa Educação, Políticas Públicas e Cidadania da UNOESC.

E-mail: marilda.schneider@unoesc.edu.br

Mônica Piccione Gomes Rios é doutora em Educação: Currículo (PUC/SP). Professora do Programa de Pós-Graduação em Educação da Pontifícia Universidade Católica de Campinas (PUC/Campinas). Pesquisadora do Grupo de Pesquisa Políticas Públicas em Educação da PUC/Campinas.

E-mail: acinompiccione@yahoo.com.br 